\title{
A Group-Specific Heterogeneous Panel Approach to the Impact of Exchange-rate Regime on Economic Growth
}

\author{
by
}

Joshua Brault

A thesis submitted to the Faculty of Graduate and Postdoctoral Affairs in partial fulfillment of the requirements for the degree of

\section{Master of Arts}

in

\section{Economics}

Carleton University

Ottawa, Ontario

(C) 2016

Joshua Brault 


\begin{abstract}
This paper proposes a group-specific heterogeneous approach known as the grouped fixed-effects to examine the impact of exchange-rate regime on economic growth. The research uses a panel consisting of 151 countries from 1999-2013. Grouped heterogeneity offers a parsimonious approach to capturing unobserved heterogeneity. Countries of similar economic institutions, economic activity, population density, and so forth, tend to adjust their long-run paths for the level of income per capita at the same speed. The methodology is able to capture speed of adjustment effects to new long-run equilibriums in a parsimonious manner, which is essential to understanding factors involved in macroeconomic performance. This paper shows that studies of economic growth have different grouped patterns of time-varying heterogeneity. Taking grouped patterns of heterogeneity into account, flexible and intermediate exchange-rate regimes are growth promoting relative to fixed-exchange rate regimes. These results are robust to a variety of sensitivity tests.
\end{abstract}




\section{Acknowledgments}

I would like to thank Professor Ba Manh Chu for his guidance, support, and knowledge throughout this research. I am also indebted to Spencer Turner for insightful discussions and comments on earlier versions of this paper. Many thanks go to Carleton University thesis committee members Nick Rowe, Matt Webb, and Mehdi Ammi. 


\section{Contents}

1 Abstract $\quad$ ii

2 Acknowledgments $\quad$ iii

3 Introduction $r$

4 Literature Review $\quad 3$

5 Methodology $\quad 8$

5.1 Unknown number of groups . . . . . . . . . . . . . . . . . . . . . . 10

6 Data 10

7 Empirical Results $\quad 12$

7.1 Parameter estimates . . . . . . . . . . . . . . . . . . . . . 13

7.2 Time-varying grouped patterns of heterogeneity . . . . . . . . . . . . . . . 15

7.3 Robustness checks . . . . . . . . . . . . . . . . . . . . . . . 19

8 Conclusion $\quad 24$

$\begin{array}{lr}\text { References } & 27\end{array}$

$\begin{array}{ll}\text { Appendix A } & 32\end{array}$

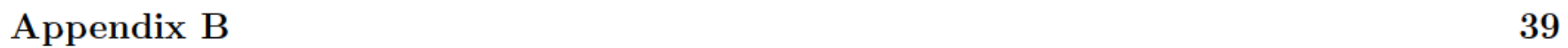

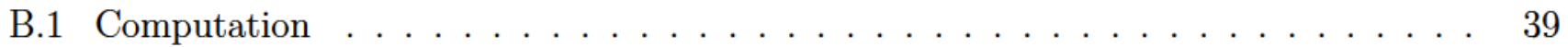

\section{List of Tables}

$1 \quad$ IMF Exchange-rate regime classification . . . . . . . . . . . . . . . . . . . . . . 12

2 Slope Parameter Estimates using GFE and FE . . . . . . . . . . . . . . . . . . . . . 14

3 Summary Statistics by Assignment . . . . . . . . . . . . . . . . . . . . . . . . 18

4 Exchange-rate regime estimates by level of trade . . . . . . . . . . . . . . . . . . . 23

5 Exchange-rate regime estimates by level of development . . . . . . . . . . . . . . . 23

6 GFE estimates . . . . . . . . . . . . . . . . . . . . . . . . 32

$7 \quad$ AREAER Exchange-rate distrubution by year . . . . . . . . . . . . . . . . . . . 32

8 Summary Statistics . . . . . . . . . . . . . . . . . . . . . 33

9 Slope Parameter Estimates using the Grouped Fixed-Effects Estimator . . . . . . . 35

10 Slope Parameter Estimates using the Grouped Fixed-Effects Estimator . . . . . . . 36

11 Slope Parameter Estimates using the Grouped Fixed-Effects Estimator . . . . . . . 37

12 Group Classification when $G=4 \ldots \ldots$. . . . . . . . . . . . . 38 


\section{List of Figures}

1 Exchange-rate regime estimates by number of groups . . . . . . . . . . . . . . . 13

2 time varying patterns $\hat{\alpha}_{g t}$ and per capita growth by group . . . . . . . . . . . . . 16

3 Average growth, investment, government expenditure and trade by group . . . . . . 17

4 Geographic depiction of groups . . . . . . . . . . . . . . . . . . . . . . . . . . . . 19

5 Kernel density of GDP growth rates by year . . . . . . . . . . . . . . . . . . . . . . . . . . . . . . . . 33

6 Objective function by number of groups . . . . . . . . . . . . . . . . . . . . . . . . . 34 


\section{Introduction}

Exchange-rate regime is one of the most important international macroeconomic choices nations can make. Yet, economic theorists have not come to a consensus regarding the relationship between exchange-rate regime and economic growth. The implication of exchange-rate regime is captured by the policy Trilemma (often referred to as the impossible trinity). The Trilemma states that fixed exchange rates, free capital flows, and independent monetary policy are mutually incompatible. A central bank may only pursue two of these objectives at any given time. The extent to which of these objectives effect long-run growth is unclear, as such, this is an empirical problem.

Given the recent financial turmoil, sovereign monetary policy has been the subject of much debate in the economic literature. This debate has focused on whether recessions have long-run effects for economic growth. Traditional monetary theory suggests that recessions are transitory in nature. Under this view, monetary policy can act as a stabilizer, but not a growth driver. The natural-rate hypothesis - as formulated by Milton Friedman - suggests that the best macroeconomic policy can hope to achieve is medium-term price stability. Expansionary monetary policy cannot keep unemployment below its natural level beyond the short-run, any attempts to do so will only lead to inflation, not economic growth (Friedman, 1968). Contrary to this initial view, seminal work by Blanchard and Summers (1986) argues that recessions have long-run growth effects through hysteresis. The hysteresis hypothesis suggests that recessions alter the natural rate of unemployment, causing a fall in output which may not be recoverable. Ball (2014) argues recessions present even stronger threats, where a long-run growth rates suffer unrecoverable consequences. These theories suggest an important role for countercyclical monetary policy - and by extension an important role for exchange-rate regime.

The traditional argument for flexible exchange rates is that, in the short-run, it is easier to achieve relative price adjustment through nominal exchange rates than through prices (Friedman, 1953). This is still considered a powerful argument for flexible exchange rates today (Rose, 2011). Proponents of fixed exchange-rate regimes argue that by eliminating exchange-rate risk and lowering transaction costs, countries can promote trade and investment in a low and stable inflation environment (Dornbusch, 2001; Dubas, Lee and Mark, 2005).

While research on the topic has been extensive, the consensus on the outcome is rather contradictory. The inconclusive results regarding exchange-rate regime's impact on economic growth stem from a variety of issues. These issues include: lack of control variables, model misspecification, and a failure to acknowledge that exchange-rate regime is only one of a broader set of international economic policies (Eichengreen and Leblang, 2003). Given the inconsistencies of both theoretical and 
empirical literature, and the multitude of ways in which exchange-rate regime may impact long-run economic growth, this thesis takes an unabashedly empirical approach to address this question.

Recent advances in econometric modeling offer attractive methods for capturing unobserved heterogeneity, a central issue to panel data. Historically, analysis of economic growth have faced challenges capturing unobserved heterogeneity and speed of adjustment effects. ${ }^{1}$ A common approach is the fixed-effects model, which captures unit-specific heterogeneity, but fails to account for different time-varying paths of heterogeneity (speed of adjustment effects). A second issue is the reliance on within variation to produce slope parameter estimates, a problem of particular importance in exchange-rate regime analysis. Econometric methods involving grouped patterns of heterogeneity offer solutions to these issues. Implicit in these models is the assumption that countries/regions of similar economic structure, economic activity, population density, and so forth, adjust their respective long-run paths for income per capita at the same speed. This assumption is grounded in the "club convergence" literature (see, e.g., Durlauf, Johnson and Temple (2005), Phillips and Sul (2007), Lin and Ng (2012), and Vogel (2013)). However, the rapid development of research in the area grouped patterns of heterogeneity presents new methodologies that have not been applied in the context of economic growth.

This thesis uses the grouped-fixed effects estimator proposed by Bonhomme and Manresa (2015). This approach allows individuals within a group to have the same unobserved effects, but groups to have vastly differing unobserved effects (see, e.g., Eq. (3) in Section 5). In this type of approach slope parameters are common across all groups. A benefit to this type of model is that the specific group makeup need not be specified by the researcher, rather only the number of groups. This novel approach is made possible through advances in machine learning techniques variable neighborhood search and extensions of the $k$-means algorithm, which are considered state of the art in solving large-scale combinatorial optimization problems (see, e.g., Hansen and Mladenovic (1997) and Forgy (1965) for an introduction to such procedures). While this simplifies the methodology in some respects, selecting the optimal number of heterogeneous groupings is statistically quite difficult, especially under conditions where $N$ (number of cross sections) is large and $T$ (number of time periods) is small. Though this thesis faces difficulty in this regard, results indicate that even in the face of this dilemma the model fits the data better than pre-existing methodologies.

Overall, the thesis finds that intermediate and flexible exchange-rate regimes are growth promoting relative to fixed regimes. These results are consistent with some of the more recent literature that is critical of pegged exchange-rates and recommend adoption of more flexible exchange-rate pol-

\footnotetext{
${ }^{1}$ Speed of adjustment effects refer to the high economic growth rates that less developed economies are able to obtain via adoption of technologies, institutional practices, law, economic structure et cetera.
} 
icy. These results are robust to a variety of specification tests including: alternative exchange-rate regime classifications, additional control variables, and controls for the endogeneity of exchange-rate regime. This thesis contributes to the literature by using a grouped heterogeneity approach to capture unobserved heterogeneity, whilst examining the impact of exchange-rate regime on economic growth.

The layout of the thesis is as follows. Section 2 covers the existing literature on the impact of exchange-rate regime on economic growth. A thorough examination of the literature is necessary to highlight the ambiguity of research findings to date. Section 3 examines the methodology of the grouped-fixed effects estimator, including a discussion of computation techniques. Section 4 discusses the data. It is important to mention that the ambiguity present in research outcomes is partially a result of the lack of transparency in classifying exchange-rate regime. Improvements have been made in this regard as the IMF has adopted a de facto approach to exchange-rate classification. Section 5 covers the empirical results, including a discussion of the selection of optimal grouping and examination of time-varying heterogeneity by group. This section concludes with a series of robustness checks necessary to validate the estimates obtained for exchange-rate policy implications. Section 6 concludes the paper and offers some suggestions as to what this research can offer to the existing stock of knowledge.

\section{Literature Review}

The ambiguity of outcomes in this research area is the result of a multitude of issues. This paper argues that one of the shortcomings is the ability of existing econometric methods used in this type of research to capture unobserved heterogeneity in a parsimonious fashion, particularly the speed of adjustment effects. Aside from these issues, the literature also suffers from lack of transparency in classification which may have contributed to the inconsistent outcomes to date. There exist three main distinct segments of literature for the impact of exchange-rate regime on economic growth, which I shall discuss below.

One segment of literature finds that floating exchange-rate regimes are growth promoting relative to more rigid regimes. Levy-Yeyati and Sturznegger (2002) conclude that higher growth rates in flexible exchange-rate regimes is a result of lower output volatility; findings show that output volatility decreases monotonically with the degree of flexibility - though these results are only robust for non-industrial countries. Eichengreen and Leblang (2003) analyze the connections between exchange-rate regime, growth and cohesion. By using a small $N$ and large $T$ approach looking at 21 countries over the period of 120 years, they find that economies with pegged exchange-rate 
regimes grow slower on average than more flexible counterparts. Theoretical justification for such a result is that independent monetary policy allows a country to insulate itself from external shocks, while fixed exchange-rate regimes are more apt at dealing with internal shocks. Ghosh (2014) finds that more flexible exchange rates lead to higher economic growth post-millennium, as well as a resurgence of intermediate regimes which is contrary to predictions following the Asian, Russian and Brazilian crises, that there would be movement to corner solutions in regime choice of pure fixes or floats (see, e.g., Eichengreen (1994); Eichengreen (1998); Summers (1999)). Bailliu, Lafrance and Perrault (2003) conclude that flexible exchange-rate regimes are growth promoting, but only for countries that are relatively open to trade and have free capital mobility. Though, the authors believe this is attributed to the monetary anchor and not to the exchange-rate regime itself. Similar results are also established in Calvo (1999) and Fischer (2001).

A second segment of literature contradicts the first by claiming that fixed exchange-rate regimes promote higher economic growth relative to more flexible regimes. Schnabl (2007) finds that fixed exchange-rate regimes promote international trade, interest rate and macroeconomic stability - and thus are growth promoting, provided that capital controls are dismantled to allow arbitrage in capital markets and international goods. Ghosh, Gulde and Wolf (2002) find that countries with pegged exchange-rate regimes experience higher economic growth rates relative to more flexible exchange-rate regimes; though their results may be an indirect consequence of regime choice on other macroeconomic variables. Results show that under fixed exchange-rate regimes both inflation and money growth are lower (the discipline effect) and there is greater confidence in the currency (the credibility effect). De Grauwe and Schnabl (2008) examine Southeastern and Central European countries from 1994-2004 and find that countries who committed to European Monetary Union (EMU) are not restricted from exchange rate fixing; those countries not belonging to the EMU can benefit in joining from increased trade and lower interest rates (Frankel and Rose, 2002 ; Dornbusch, 2001). Other studies corroborate these results with the general consensus being that fixed exchangerate regimes promote macroeconomic stability and ultimately economic growth through avenues such as: lower transaction costs, increased trade, and investment (Moreno, 2000; Moreno, 2001; Dubas, Lee and Mark, 2005).

These results are further compounded by a third strand of literature which finds exchange-rate regime to have no effect on long-term growth. De Vita and Kyaw (2011) finds that controlling for monetary policy framework is essential to understanding the effects of exchange-rate regime on growth, and by controlling for such framework, they find no systematic link between regime and growth. These results are supported by Miles (2006) who concludes that no independent effect of exchange-rate regime on growth is present once hard-to-observe policy distortions and macroeco- 
nomic imbalances are accounted for. Bleaney and Francisco (2007) examine exchange-rate regime and growth from 1984-2001 and find no significant impact of exchange-rate regime on output. The analysis regresses growth rates on its own lags, exchange-rate regime dummies and time dummies, though as Patreski (2009) notes: what one can learn from the work of Bleaney and Francisco (2007) is slim as improper growth framework and general lack of consideration for endogeneity and robustness checks are offered. Ghosh, Ostry, Gulde and Wolf (1997) conclude that different samples often lead to varied conclusions about the impact of exchange-rate regime on growth. Results showed that inflation was much lower under fixed exchange-rate regimes, while productivity growth was higher under floating regimes. Miles (2008) employs a difference-in-differences approach and finds that regime choice does not play a significant role in growth. Furthermore, the results draw into question the correlation between floating rates and inflation, implying an omitted variable bias. The implication of many of the studies above indicates that proper framework is essential whilst examining the impact of exchange-rate regimes on economic growth.

A major contributor to the cause of ambiguity of exchange-rate regime effects on growth has been the classification of regime. The early literature was based on de jure classifications provided by the International Monetary Fund in the Annual Report on Exchange Arrangements and Exchange Restrictions (AREAER); de jure classifications are self-reported exchange-rate regime, as opposed to de facto which are evidence based exchange-rate regime classification. This resulted in discrepancies, as gaps arose between what countries were reporting and what was occurring. For example, Calvo and Reinhart (2002) note that countries may exhibit a fear of floating, whereby they intervene in the foreign exchange market to limit exchange-rate variability, though claim to let their exchange-rate float. This is prominent in emerging markets with credibility issues, where deliberate policy to stabilize exchange rates comes at the cost of interest rate and reserve volatility. The inconsistencies regarding regime exchange-rate classification necessitated the creation of independent de facto exchange-rate regime classifications. While the IMF transitioned to a de facto classification approach in 1998, the literature commonly uses alternate classifications as a way to test robustness. As Eichengreen and Razo-Garcia (2011) note, it is unsettling that the literature is based upon these indices, yet they often do not agree. One classification will regard a country as a fix, while another will classify it a float. A further issue is that these inconsistencies are not random, and are greatest in emerging and developing countries (Eichengreen and Razo-Garcia, 2011). Such issues must draw into question the validity of the literature. The time frame of the proposed research benefits from the increased emphasis on classification transparency, from 1998 onwards the IMF has published a classification of countries' de facto exchange rate arrangements, which is expected to yield greater consistency (Habermeier, Kokenyne, Veyrune and Anderson, 2009). Recent de facto exchange-rate 
regime classifications appear to support this hypothesis (Bleaney and Tian, 2014). In light of this increased transparency, it is still a standard sensitivity test to consider alternate de facto exchangerate regime classifications. For example, one alternative measure this paper considers is a flexibility index similar to Bayoumi and Eichengreen (1998) which uses the fluctuations in exchange-rate and foreign exchange reserves:

$$
F_{i, t}=\frac{\Delta_{E_{i, t}}}{\Delta_{F E R_{i, t}}+\Delta_{E_{i, t}}}
$$

Where $F_{i, t}$ is the flexibility of country $i$ at time $t, \Delta_{E}$ is the changes in exchange rates for country $i$ at time $t$ and $\Delta_{F E R}$ is the changes in foreign exchange reserves for country $i$ at time $t$; all changes are in log values. This provides an index between zero and one, with higher value denoting a greater degree of exchange-rate flexibility. Several alternative de facto measures exist with varying methodology (see, e.g., Bleaney and Tian (2014); Levy-Yeyati and Sturznegger (2002); Ilzetzki, Reinhart and Rogoff (2010)).

Another issue in studying the impact of exchange-rate regimes on macroeconomic performance, is accounting for other determinants of economic growth. Miles (2008) notes that failure to account for these factors can lead to upward biased estimates of the variables in question. Two factors which are essential to control for are currency crises and banking crises. Currency crises result when doubts arise that a central bank may not have enough foreign exchange reserves to maintain their fixedexchange rate, which can lead to speculative attacks as large amounts of domestic currency are sold fearing devaluation or debt default. Such crises have a negative impact on economic growth as they often result in recession with impacts on other nominal and real variables. Examples include: Mexican Peso crisis of 1994, Asian crisis of 1997, Russian crisis of 1998 and Argentine crisis of 2002. Banking crises can occur in tandem with currency crises or independently. These crises result when a country's financial and banking sector experiences a large number of defaults and financial entities cannot fulfill financial contracts in a timely manner (Contessi and El-Ghazaly, 2011). Evidence suggests that banking crises are more severe when accompanied by currency crises, but both events result in a significant drop in output (Cecchetti, Kohler and Upper, 2009).

Capital controls play an important role in international finance as they limit the convertibility of domestic currency and act as barrier to capital flows. Controls arose as a solution to balance-ofpayments problems and play an important role in developing economies who often have less than desirable foreign exchange reserves. As Cordero and Mentecino (2010) note, capital controls present an alternative to governments who wish to pursue policy with reasonable levels of inflation while maintaining a competitive and stable real exchange-rate. There exist a variety of capital control 
measures; following Miniane (2004), this paper creates a capital control index via de jure information from IMF AREAER reports. These variables may have significant impacts on macroeconomic performance, controlling for such is essential in discerning the impacts of exchange-rate regime on economic growth - I will address this issue in Section 5.3.

Much of the literature has relied heavily upon two-way fixed-effects models to control for unit specific and time-varying heterogeneity (Eichengreen and Razo-Garcia (2011); De Vita and Kyaw (2011), to name a few). The approach is flexible as it puts no restrictions on the relationship between unobserved effects and covariates. However, as Bonhomme and Manresa (2015) note, allowing for as many parameters as individual units comes at a cost in these short panels. These costs can contaminate common parameters and subject them to incidental parameter bias (Nickel, 1981; Hahn and Newey, 2004). Two-way fixed-effects also imposes rigidity as all cross-sections are subject to the same unobservable time heterogeneity. This presents issues, as this paper argues there is significantly time-varying heterogeneity, which is better captured using grouped fixed-effects. Group heterogeneity - with respect to economic growth - is captured by the literature on club convergence; literature suggests countries/regions with lower levels of macroeconomic prosperity may achieve higher economic growth rates. Alexiadis and Tomkins (2010) examine EU states from 1995-2006 and show that countries with a high technology gap garner higher growth rates - but only if they exhibit sufficient levels of infrastructure to absorb these technological differences. Canova (2004) generalizes this result and suggests that convergence around different equilibrium levels may be the result of various factors, including: endowment levels of factors of product, technologies, similar preferences, and government policies, which become more similar over time within regional groups. Lee, Pesaran and Smith (1997) test convergence club heterogeneity and find that unobservable time effects are indeed heterogeneous with two time-varying patterns being negative and two being positive when examining 69 countries over the sample 1965 to 2003 . Other researchers find similar results consistent with the theory of club convergence (Phillips and Sul (2007); Lin and Ng (2012); Bandyopadhyay (2011); Massoumi and Wang (2008); Andrade, Madalozzo and Pereira (2004), to name a few). These findings illustrate the dilemma in using two-way fixed-effects; the speed of adjustment effect is non-linear and fixed-effects is unable to capture this in an appropriate manner. Implicit in this methodological approach, the research rejects studies which employ a log-value ratio of GDP - often relative to U.S. GDP - which suggests that speed of adjustment effects are identical for countries of a given income level, regardless of location and economic attributes (for example, Ghosh, 2014).

To the best of my knowledge, examining the impact of exchange-rate regime on economic growth has not been approached using grouped patterns of heterogeneity. The aim of this research is to 
gain insights into the impacts of exchange-rate regime choice on economic growth by using a new econometric approach to clarify the ambiguity present in the literature. This research will focus on the impacts of exchange-rate regime in the 21st century, gaining insights into the performance of exchange-rate policy in the most recent global economic events.

\section{$5 \quad$ Methodology}

This thesis uses a novel approach known as the grouped fixed-effects (see Bonhomme and Manresa (2015)). This thesis argues that, whilst examining the impact of exchange-rate regimes on economic growth, in the presence of group patterns of heterogeneity, the grouped fixed-effects (GFE) is a superior method to the time-invariant fixed-effects estimator in capturing speed of adjustment effects. $^{2}$

A useful demonstration is to illustrate the differences between traditional two-way fixed-effects and grouped fixed-effects. For country $i$ at time $t$ : let $\Delta y^{p c}$ denote the growth rate of GDP per capita; Furthermore, let $x$ denote the vectors $x_{i, t}$ for all country $i$ at time $t$, and let $\theta$ denote a $k \times 1$ vector of explanatory variables; including our exchange-rate regime variables. $\epsilon_{i, t}$ denotes an independent and identically distributed error term. Equation (2) represents the standard two-way fixed-effect model, with country level time-invariant heterogeneity accounted for in $\alpha_{i}$. The within estimator imposes the restriction that $\lambda_{t}$ be the same for all countries:

$$
\Delta y_{i t}^{p c}=\alpha_{i}+\lambda_{t}+x_{i t}^{\prime} \boldsymbol{\theta}+\epsilon_{i t}
$$

Equation (3) represents the standard grouped fixed-effect model:

$$
\Delta y_{i t}^{p c}=\boldsymbol{\alpha}_{g(i), t}+x_{i t}^{\prime} \boldsymbol{\theta}+\epsilon_{i t}
$$

where $g(i) \equiv g_{i}:[1, \ldots, N] \rightarrow[1, \ldots, G]$ represents a group-assignment function. The model assumes that countries can be categorized into groups by $g=1, \ldots, G$. By categorizing into groups the GFE model allows relaxation of the constraint on the time-varying heterogeneity relative to traditional fixed-effects. GFE allows for a time effect $\alpha_{i t}=\alpha_{g(i), t}$ where the unobserved effects are the same for all countries in a given group, but allowing different groups to have significantly

\footnotetext{
${ }^{2}$ This paper uses algorithms provided by Stephane Bonhomme and Elena Manresa in calculating grouped patterns of heterogeneity. See http://www.cemfi.es/ bonhomme/ for executable codes.
} 
different patterns (i.e., the model assumes the world can be divided into regions with similar patterns in these unobservables). This estimator does not require the researcher to specify the groups, rather they are estimated with the parameters. As Grunewald, Klasen, Martinez-Zarzoso and Muris (2015) note there are two further advantages to using the GFE: first, the time-varying groups are better suited to deal with endogeneity due to unobserved heterogeneity; second, for analysis where the inter-temporal variation is small, the fixed-effects estimator takes away a large amount of the between-country variation.

The model contains three parameters: $\alpha$ represents the set of all $\alpha_{g t}$ 's, $\gamma$ the set of all $g_{i}$ 's and $\theta$ which is the parameter vector common across all units. The parameters belong to the following spaces: $\alpha \in \mathcal{A} \forall g \in\{1, \ldots, G\}$ and $t \in\{1, \ldots, T\}$; group membership variables $g_{i} \forall i \in\{1, . ., N\}$, and groupings $\gamma \in \Gamma_{G}$; parameter space for covariates $\theta \in \Theta$. The estimation of the grouped fixed-effects estimator is defined as the solution to the following minimization problem:

$$
(\hat{\boldsymbol{\theta}}, \hat{\boldsymbol{\alpha}}, \hat{\gamma})=\underset{(\boldsymbol{\theta}, \alpha, \gamma) \in \Theta \times A^{N T} \times T_{G}}{\operatorname{argmin}} \sum_{i=1}^{N} \sum_{t=1}^{T}\left(\Delta y_{i t}^{p c}-\boldsymbol{x}_{i t}^{\prime} \boldsymbol{\theta}-\boldsymbol{\alpha}_{g_{i} t}\right)^{2}
$$

The minimization solution maps $N$ individual units into $G$ groups then estimates common parameters $\theta$ and group-specific effects $\alpha$ (for a comprehensive estimation description, see Appendix B).

The GFE requires several assumptions to be satisfied to ensure consistent estimates, some of which are unique to the approach. Some of the more important assumptions are:

1. Grouped fixed-effects requires that groups be well separated.

2. Errors may be spatially correlated. While the model does not impose any spatial correlation, there are no restrictions. Spatial properties are the result of the estimation. Country growth may exhibit this spatial correlation as countries often share similar traits with surrounding economies, leading to similar growth patterns.

3. $\alpha_{g, t}$ and $x_{i, t}$ are allowed to be arbitrarily correlated.

4. $E\left(x_{i, t} \epsilon_{i, t}\right)=0$. If this assumption is not satisfied GFE is generally inconsistent.

5. Persistent covariates are not permitted

Given the assumptions are satisfied the GFE has been shown to be consistent and follow an asymptotic normal distribution. The GFE offers several alternative specifications, which include: 
allowing for unit-specific heterogeneity, linear constrained time patterns, adding prior information, and applicability to non-linear models.

\subsection{Unknown number of groups}

A requirement of grouped fixed-effects is that the researcher must specify the number of groups when group membership is unknown. Lin and Ng (2012) give an informal approach, which is to graph the values of the objective function by number of groups and find the point at which the objective function begins to flatten. An alternative approach is to minimize the following Bayesian Information Criteria (BIC):

$$
B I C(G)=\frac{1}{N T} \sum_{i=1}^{N} \sum_{t=1}^{T}\left(\Delta y_{i t}^{p c}-\boldsymbol{x}_{i t}^{\prime} \hat{\boldsymbol{\theta}}^{(G)}-\hat{\boldsymbol{\alpha}}_{i t}^{(G)}\right)^{2}+\hat{\sigma}^{2} \frac{G T+N+K}{N T} \ln N T
$$

Where $G$ is the number of groups, $N$ is the number of group membership variables (cross-sections), $T$ is the number of time periods, and $K$ is the number of common parameters. $\hat{\sigma}^{2}$ is an estimate of the variance $\epsilon_{i t}$. This variance is estimated by following (the researcher must specify $G_{\max }$ ):

$$
\hat{\sigma}^{2}=\frac{1}{N T-G_{\max } T-N-K} \sum_{t=1}^{T}\left(\Delta y_{i t}^{p c}-\boldsymbol{x}_{i t}^{\prime} \hat{\boldsymbol{\theta}}-\hat{\boldsymbol{\alpha}}_{\hat{\boldsymbol{g}}_{i}(\tilde{\boldsymbol{\theta}}, \tilde{\boldsymbol{\alpha}}) t}\right)^{2}
$$

Careful consideration of group membership is important because when $G<G^{0}$ (we refer to $G^{0}$ as the true number of groups) and unobserved effects are correlated with covariates, estimates of $\hat{\theta}$ are generally inconsistent due to omitted variable bias. When $G>G^{0}$ common parameters $\hat{\theta}$ remain consistent for $\theta^{0}$ when $N, T \rightarrow \infty$ at the same speed. If $N \rightarrow \infty$ faster than $T$, which is the case in this research, then the BIC for estimating optimal groups acts only as a conservative estimate (Bonhomme and Manresa, 2015).

\section{Data}

The sample contains a balanced panel with yearly observations for 151 countries over the period 1999-2013, which is a more recent time-frame than the existing literature. The data set contains 2,065 observations. GDP per capita growth rate and other control measures are obtained from the World Bank's World Development Indicators. The control variables include: General government 
expenditure $\left(G o v / G D P_{i t}\right)$, which consists of purchases of goods and services via government as a $\%$ of GDP. Government expenditure can promote growth by stimulating employment and demand. At the same time, excessive budget deficits or debt can harm economic growth; the impact of government expenditure is ambiguous. Gross capital formation (Investment/GDP $P_{i t}$ ) consists of additions to fixed assets plus net changes in the level of inventories as \% of GDP. I expect gross capital formation to have a positive impact on economic growth. Trade (TradeOpenness ${ }_{i t}$ ) is the sum of exports and imports as a \% of GDP. Trade promotes specialization and transfer of technology, I expect trade to have a positive impact on economic growth. I include other control variables often included in empirical growth regressions, which include: Population growth $\left(P O P G R_{i t}\right)$ is the \% change in population from previous year; Education $\left(S E C_{i t}\right)$ is the duration of secondary schooling mandated in the country; Population $\left(P O P_{i t}\right)$ is the total population, which consists of all residents regardless of legal status or citizenship; Terms of Trade (TermsofTrade $i t$ ) which is the capacity to import minus exports of goods and services in constant prices; and Life expectancy (LifeEXP $P_{i t}$ ), which is the average years an infant at birth is expected to live based on prevailing patterns. Table 8 shows the descriptive statistics for these variables.

Exchange-rate regime classification is provided by the IMF Annual Report on Exchange Arrangements and Exchange Restrictions (AREAER). The publication contains information on exchangerate regime and factors relevant to classification. The collapsing of exchange-rate classification used in this paper deserves some mention. AREAER classification was comprised of 8 categories until 2007, at which time 3 additional categories were included. Following Ghosh (2014) I collapse the categories into broader aggregates of fixed, intermediate and floating exchange-rate regimes (see Table 1). The additional categories added in 2008 are added to intermediate regimes. Given the divided literature, the expected sign of exchange-rate regime is ambiguous.

The alteration of AREAER classification has potentially important implications due to the drastic change in the distribution of exchange-rate regimes. While there exists variation from year to year, the drastic increase in intermediate exchange-rate regimes in 2008 is largely a result of the additional categories added in the 2008 report. ${ }^{3}$ The issue regarding classification reconfiguration, coupled with concerns of exchange-rate regime transparency, require sensitivity checks on exchangerate regime classification. While there has been substantial improvements in transparency of regime, a standard robustness check is to use alternate exchange-rate regime classifications to verify the results. This analysis makes use of an alternate classification provided by Shambaugh (2004). The classification method determines base currencies for each country and tracks these fluctuations relative to a reference currency. To prevent misclassification via a one time currency devaluation,

\footnotetext{
${ }^{3}$ Table 7 denotes exchange-rate regime distribution by year.
} 
Table 1: IMF Exchange-rate regime classification

\begin{tabular}{lll}
\hline & Pre-2007 & Post-2007 \\
\hline \hline \multirow{2}{*}{ Fixed } & Exchange arrangement with no separate legal tender & No separate legal tender \\
& Currency Board Arrangement & Currency Board \\
& Conventional pegged arrangement & Conventional Peg \\
\hline \multirow{2}{*}{ Intermediate } & Pegged exchange rate within horizontal bands & Stabilized arrangement \\
& Crawling peg & Crawling peg \\
& Crawling band & Crawl-like arrangement \\
& & Other managed arrangement \\
& & Crawling band \\
\hline \multirow{2}{*}{ Floating } & Managed float with no pre-determined path & Pegged exchange rate within horizontal bands \\
& Independently floating & Free floating \\
\hline
\end{tabular}

the methodology examines monthly data and considers pegs if eleven out of the twelve months are consistent with a peg; in addition single year pegs are not considered fixed as they are quite possibly not intentional pegs. These classifications take on two categories: peg and non-peg. A final exchange-rate flexibility index is created similar to Bayoumi and Eichengreen (1998), which uses the percentage changes in exchange-rate and foreign exchange reserves to give a zero to one index of exchange-rate flexibility.

\section{Empirical Results}

In this section I discuss the estimates of the slope parameters, grouped patterns of heterogeneity and group membership. The section performs several sensitivity analyses using different techniques and exchange-rate regime classifications to ensure robust results.

The estimation framework is based on a traditional Solow growth model, which accounts for determinants of economic growth:

$$
\begin{aligned}
\Delta y_{i t}^{p c}=\alpha_{g(i), t}+\delta_{1} \text { IntermediateRegime }_{i t} & +\delta_{2} \text { FlexibleRegime }_{i t}+\beta_{1} \text { Investment } \text { GDP }_{i t} \\
+\beta_{2} \text { TermsofTrade }_{i t}+ & \beta_{3} \text { TradeOpeness }_{i t}+\beta_{4} \text { Gov } / G D P_{i t}+\beta_{5} \text { POP }_{i t} \\
& +\beta_{6} \text { POPGR }_{i t}+\beta_{7} S E C_{i t}+\beta_{8} \text { LifeEX }_{i t}+\epsilon_{i t}
\end{aligned}
$$

where $\alpha_{g(i), t}$ is the grouped-fixed effect term. $\delta_{1}$ and $\delta_{2}$ are the slope parameters of interest indicating intermediate or flexible exchange-rate regimes, which are benchmarked to fixed exchange-rate regimes. 


\subsection{Parameter estimates}

Figure 1 plots the estimates of $\delta_{1}$ and $\delta_{2}$ for the intermediate and flexible exchange-rate regimes using different group membership specifications. ${ }^{4}$ As the number of groups increases the consistency of the estimates becomes more apparent. If variability of the slope parameter is high between groups this suggests that $G<G^{0}$, this slope parameter variation is the result of omitted variable bias (Bonhomme and Manresa, 2015).

Figure 1: Exchange-rate regime estimates by number of groups
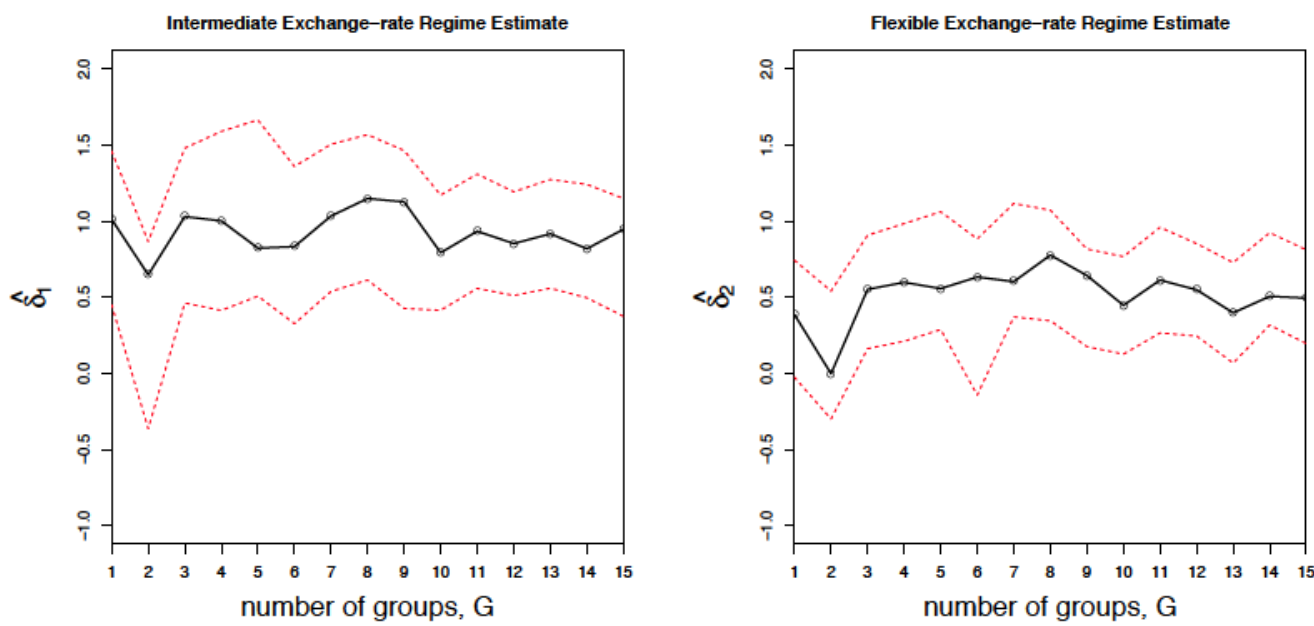

Note: The graphs depict the number of groups on the $\mathrm{x}$-axis and the slope parameter associated with exchange-rate regime type on the y-axis. 95\% confidence intervals are denoted by the red lines and slope parameter estimates denoted in the black line.

Table 6 reports the value of the objective function, BIC, $R^{2}$, and estimates by number of groups and contrasts these results to a two-way fixed-effects model. The objective function decreases as the number of groups increases; the value of the objective function decreases by roughly $40 \%$ when $G=5$ compared to $G=1$. The value of the objective function decreases by roughly $70 \%$ when $G=15$. The last row in the table shows a two-way fixed-effect model; the GFE objective function is lower when $G>3$ suggesting that there exists a considerable amount of time-varying heterogeneity in the data. Selecting the optimal choice of groups is problematic as the finite sample has $N \rightarrow \infty$ faster than $T$ and the estimation of group membership via BIC only acts as conservative estimate. The BIC shows that the optimal grouping is $G=12$. In conjunction with Figure 1 , the estimates of exchange-rate regimes have little variation between $G=3$ and $G=15$. According to Bonhomme

\footnotetext{
${ }^{4}$ All estimates were calculated using the Variable Neighborhood Search algorithm (number of starting values 10; number of neighbors 10 ; number of iterations 10 ).
} 
and Manresa (2015) this is consistent with the true number of groups $\left(G^{0}\right)$ being smaller than 12. Applying the informal approach suggested via Lin and Ng (2012) - examining the slope of objective function across groups - yields consistent conclusions with the BIC approach, that the optimal grouping is close to 12 (see Table 6). ${ }^{5}$ However, the fundamental conclusions regarding exchange-rate regime and economic growth remain unchanged when $G \geq 3$. For exposition of new methodology, this paper examines the case where $G=4$.

Table 2: Slope Parameter Estimates using GFE and FE

\begin{tabular}{|c|c|c|}
\hline & Fixed-effects & GFE, $G=4$ \\
\hline \multirow[t]{2}{*}{ Govt. Expenditure } & $-0.082^{* * *}$ & $-0.033^{* *}$ \\
\hline & {$[-0.1327,-0.0303]$} & {$[-0.0580,-0.0073]$} \\
\hline \multirow[t]{2}{*}{ Investment } & $0.178^{* * *}$ & $0.142 * * *$ \\
\hline & {$[0.1444,0.2111]$} & {$[0.1181,0.1649]$} \\
\hline \multirow[t]{2}{*}{ Trade as \% of GDP } & $0.013^{* *}$ & $0.009 * * *$ \\
\hline & {$[0.0015,0.0237]$} & {$[0.0061,0.0110]$} \\
\hline \multirow[t]{2}{*}{ Terms of trade } & $-1.05 \mathrm{e}-15$ & $-6.25 \mathrm{e}-16$ \\
\hline & {$[-1.41 \mathrm{e}-14,1.62 \mathrm{e}-14]$} & {$[-5.35 \mathrm{e}-15,4.10 \mathrm{e}-15]$} \\
\hline \multirow[t]{2}{*}{ Population Growth } & $-0.811^{* * *}$ & $-0.394^{* * *}$ \\
\hline & {$[-1.0590,-0 .-0.5626]$} & {$[-0.6893,-0.0990]$} \\
\hline \multirow[t]{2}{*}{ Log(total population) } & $3.55^{* *}$ & $0.179^{* * *}$ \\
\hline & {$[0.6111,6.5054]$} & {$[0.0803,0.2778]$} \\
\hline \multirow[t]{2}{*}{ Education } & $0.938^{* *}$ & -0.123 \\
\hline & {$[0.1488,1.7267]$} & {$[-0.2988,0.0534]$} \\
\hline \multirow[t]{2}{*}{ Life expectancy } & $0.090^{* *}$ & $-0.025^{*}$ \\
\hline & {$[-0.0679,0.2474]$} & {$[-0.0509,0.0019]$} \\
\hline \multirow[t]{2}{*}{ Intermediate regime } & $-0.892^{* *}$ & $1.002^{* * *}$ \\
\hline & {$[-1.6209,-0.1628]$} & {$[0.4137,1.5903]$} \\
\hline \multirow[t]{2}{*}{ Flexible regime } & $-0.975^{* * *}$ & $0.598 * * *$ \\
\hline & {$[-1.6210,-0.3308]$} & {$[0.2112,0.9840]$} \\
\hline$R^{2}$ & 0.4393 & 0.4862 \\
\hline $\mathrm{AIC}$ & $10,715.84$ & $10,605.53$ \\
\hline $\mathrm{BIC}$ & $10,851.03$ & $10,937.87$ \\
\hline SSE & $21,184.62$ & $19,413.35$ \\
\hline $\mathrm{N}$ & 2,065 & 2,065 \\
\hline
\end{tabular}

Note: Script-size numbers in square brackets denote the bounds of the $95 \%$ confidence intervals. ${ }^{*}, * * * * *$ indicate significance at the $10 \%, 5 \%$ and $1 \%$ level.

As seen in Table 6 , an examination of the slope parameters reveals that, after taking into account time-varying heterogeneity, intermediate and flexible exchange-rate regimes have a positive

\footnotetext{
${ }^{5}$ A graphical representation of the objective function across groups is provided in Figure 6.
} 
impact on economic growth relative to fixed-exchange rate regimes. The slope parameter for intermediate and flexible exchange-rate regimes is significant at the $1 \%$ level. An interesting comparison is to examine the conclusions offered from the GFE to a traditional time-invariant fixed-effects model. The result that more flexible exchange-rate regimes are growth promoting is contradicted using two-way fixed-effects. The fixed-effects model suggests that both intermediate and flexible exchange-rate regimes have a negative impact on economic growth at the $5 \%$ and $1 \%$ levels. It is worrisome that opposite conclusions are drawn based on methodology, though this may explain some of the ambiguity in the existing literature. These differing results suggest that when time-varying heterogeneity is not accounted for in an efficient manner, estimation yields different conclusions. Implicit in this outcome is that the GFE is a much more parsimonious approach by its relative fit to the data, suggesting that time-invariant fixed-effects may suffer from contaminated bias in short panels.

The remaining control variables exhibit predictable outcomes: I find that government expenditure has a negative slope parameter significant at the $5 \%$ level; population growth also boasts a negative slope parameter, it is significant at the $1 \%$ level. Investment, trade and log of total population are growth promoting and significant at the $1 \%$ level. Life expectancy has a negative slope parameter significant at the $10 \%$ level, however the effect appears to be ambiguous as negative and positive values fall within the $95 \%$ CI. Terms of trade and education also have a negative coefficients, though results suggest that these variables are not significant determinants of economic growth. The sign and significance of these results are generally consistent with the literature, while the slope parameter estimates vary in size - this may be attributed to sample selection. ${ }^{6}$

\subsection{Time-varying grouped patterns of heterogeneity}

The improvements in the objective function when using GFE compared to fixed-effects indicate that a substantial amount of grouped time-varying heterogeneity is present in economic growth, which is consistent with hypothesis put forth in Section 1.

Figure 2 depicts these grouped heterogeneous time-patterns captured in $\hat{\alpha}_{g t}$ when $G=4$, these time-trends are benchmarked to the year 1999. Group 1 shows erratic movement with large positive and negative unobserved effects, there appears to be no distinguishable trend in this group. Group 2 depicts countries with consistent negative time-varying unobserved heterogeneity, the values of these time-effects worsen throughout the sample. Groups 3 and 4 follow similar time paths with positive unobserved effects for much of the sample, these two groups both exhibit downward movement

\footnotetext{
${ }^{6}$ Replication code for these results can be found at https://goo.gl/azjM9W
} 
Figure 2: time varying patterns $\hat{\alpha}_{g t}$ and per capita growth by group
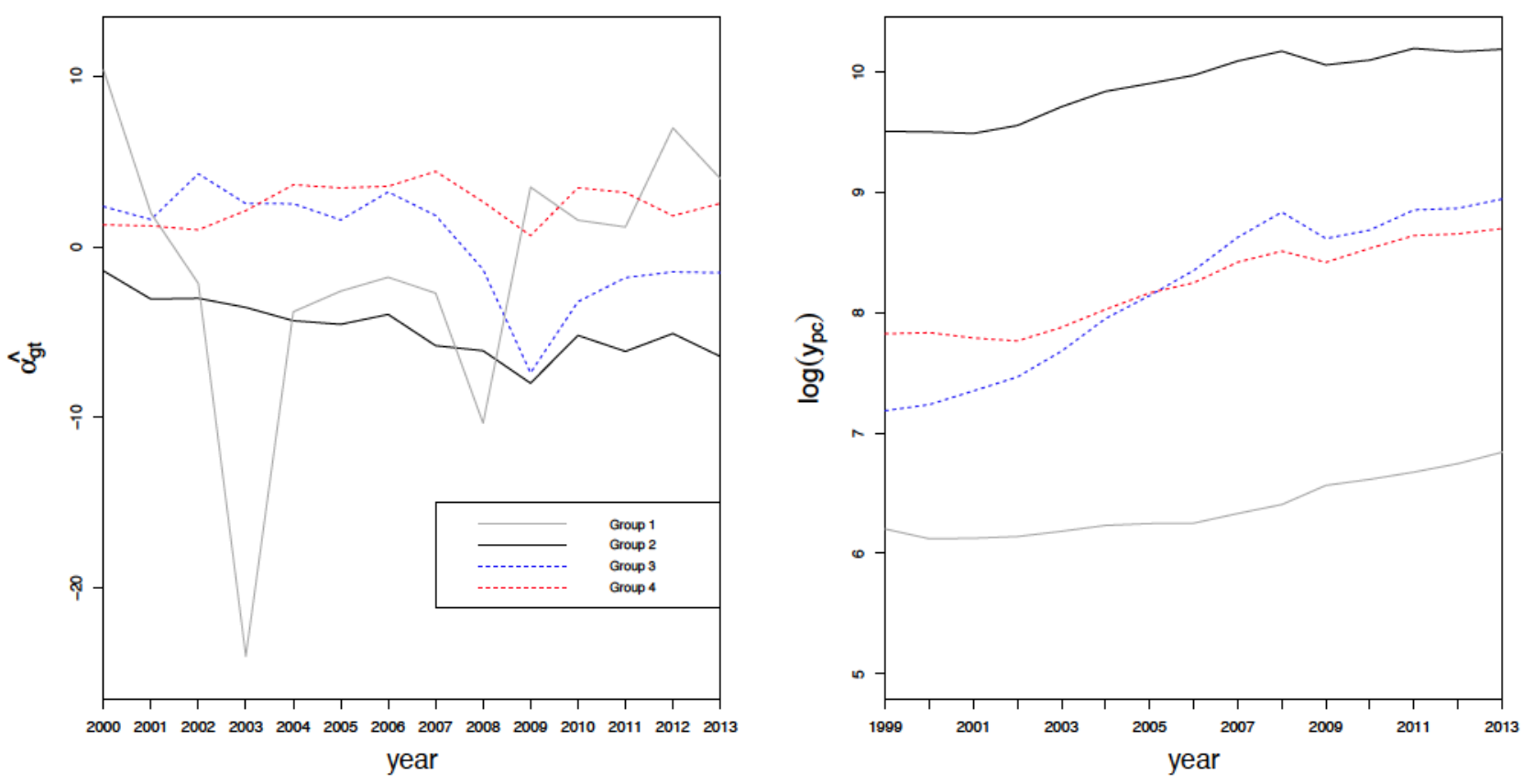

during the years 2007-2009, though the downward movement captured in group 3 is considerably worse than group 4.

The time-varying heterogeneity for countries affected by the Great Recession stemming from the financial crisis is important, as it was one of the motivating reasons for choosing this time period. Group 2 contains the majority of OECD countries, considering the Great Recession stemmed from a financial crisis one would expect these countries to suffer the most. While Group 2 sees negative unobserved time-effects during 2007-2009, one would expect more severe repercussions from the Great Recession, comparable to the movement seen in Group 3. An explanation for this lack of downward unobserved effects in group 2 is that the model is able to capture much of the growth hampering effects resulting from the financial turmoil. Indeed, this hypothesis is confirmed upon inspection of the covariates, both investment and trade (positively related to growth) fall during the years 2007-2009, while government expenditure (negatively related to growth) rises during the same period (Figure 3 shows the movement of relevant covariates over the sample by group). This interpretation could be extended across other groups, as we see the same pattern in macroeconomic indicators across groups. Table 3 provides summary statistics by group which allow us to reach further conclusions about group membership.

Groups 2 and 4 makes up roughly $80 \%$ of the sample, suggesting that the majority of countries 
Figure 3: Average growth, investment, government expenditure and trade by group
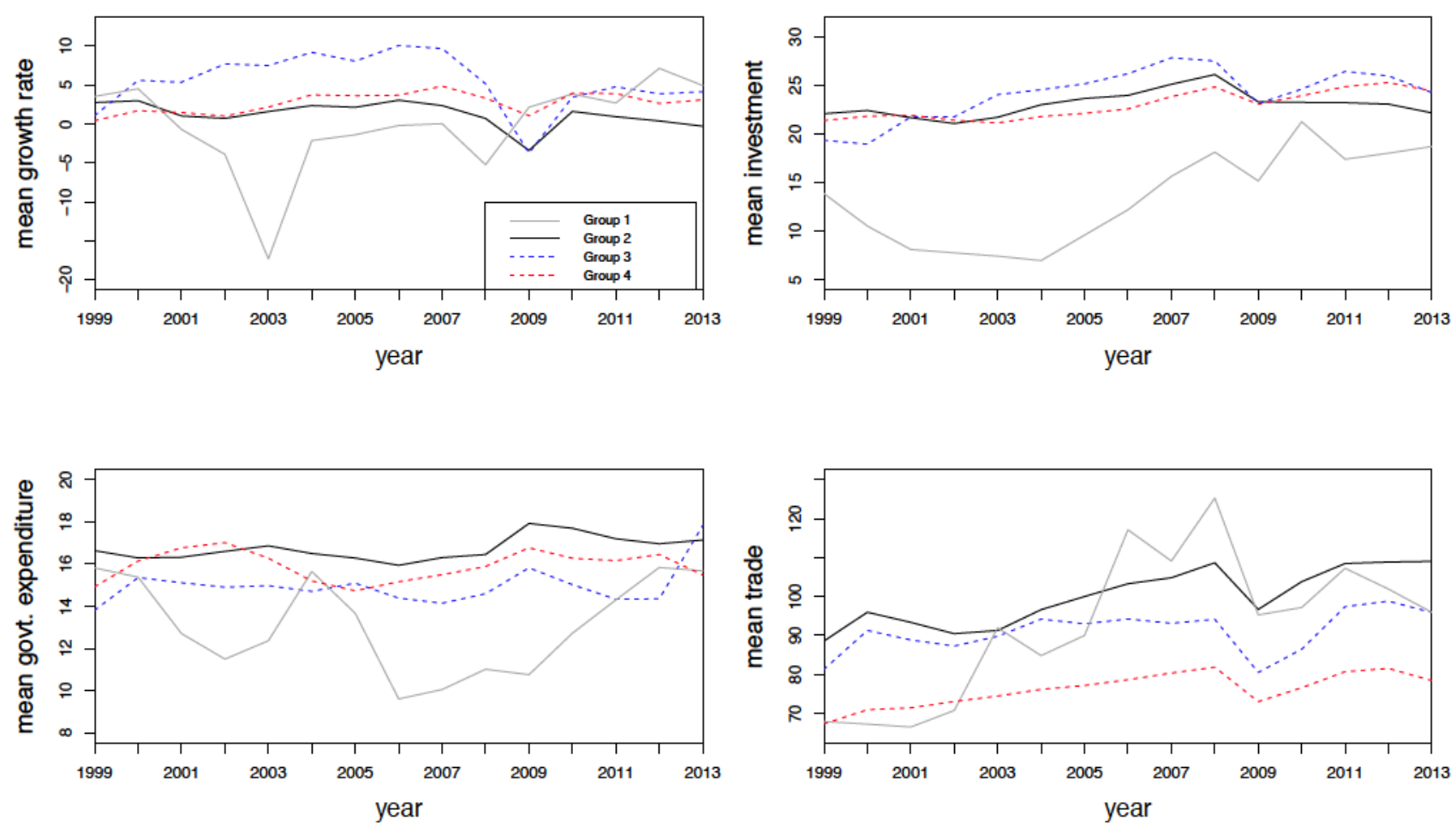

Note: investment, government expenditure and trade are calculated as a percentage of GDP.

have similar unobserved time-varying heterogeneity. Group 4 is mainly comprised of low to middleincome economies as classified by the World Bank Atlas Method with above average mean economic growth rates. Group 4 is mainly South American, African and Middle-Eastern nations, though it does contain 6 OECD members which include: Chile, Iceland, Israel, Poland, Slovak Republic and Turkey. Group 2 is predominantly high-income 'western countries'. Group 2 has the highest mean GDP per capita while experiencing relatively low economic growth rates, the group contains 27 of the 34 OECD countries. Group 3 contains 23 countries which are mainly middle-income nations. Group 3 has high economic growth relative to the other groups and contains only 1 OECD member, Estonia. Group 1 only contains 3 nations which have extremely volatile economic growth (Zimbabwe, Cote d'Ivoire and Liberia). These countries have an extremely low mean GDP per capita and have a negative average growth rate over the sample period. The composition of groups indicates we have effectively 4 types of groups: one, a small section of low income countries with extremely volatile macroeconomic performance; two, the majority of the developed world with very 
high income per capita and relatively low economic growth rates; three, low to middle income with very high average growth rates; four, low to middle-income nations experiencing above average economic growth.

Table 3: Summary Statistics by Assignment

\begin{tabular}{l|cccc}
\hline & \multicolumn{4}{|c}{ Assignment } \\
\hline Variable & $(1)$ & $(2)$ & $(3)$ & $(4)$ \\
\hline \hline Number of Countries (N) & 3 & 62 & 23 & 63 \\
Mean GDP per capita (\$) & 606.97 & $20,564.02$ & $4,339.29$ & $3,951.27$ \\
Mean growth rate (\%) & -0.129 & 1.27 & 5.45 & 2.72 \\
Percentage of fixed exchange-rate regimes (\%) & 60 & 37.74 & 28.78 & 36.32 \\
Percentage of int. exchange-rate regimes (\%) & 17.78 & 14.19 & 25.52 & 16.08 \\
Percentage of flexible exchange-rate regimes (\%) & 22.22 & 48.07 & 45.7 & 47.60 \\
Low-income economies (\%) & 84.44 & 18.82 & 29.28 & 37.03 \\
Middle-income economies (\%) & 15.56 & 26.99 & 60.87 & 56.40 \\
High-income economies (\%) & 0 & 54.19 & 9.86 & 6.56 \\
Number of OECD members & 0 & 27 & 1 & 6
\end{tabular}

Note: Country income classification is based upon gross national income per capita with boundaries set via World Bank Atlas Method. Countries with GNI less than $\$ 1,045$ are considered low-income; $\$ 1,046-\$ 12,735$ are considered middle-income; and countries with greater than $\$ 12,735$ are considered high-income countries. The calculations are done yearly meaning that a country can belong to several groups income groups throughout the sample.

Examining Figure 2 we can see the growth of GDP per capita by group. Groups 1 and 2 have relatively stable growth in GDP per capita over the sample, while group 3 and 4 has drastically higher growth over the period 2001-2008. It is important to distinguish that the increases in GDP per capita in groups 3 and 4 does not automatically indicate speed of adjustment effects, as this growth could be captured by macroeconomic variables in the model. Speed of adjustment refers to the consistent positive unobserved effects not captured by the model, reported in $\alpha_{g, t}$. This suggests that for groups 1 and 2 traditional fixed-effects may be suitable, but not for group 3 and 4 , as it clearly shows speed of adjustment effects to a new long-run equilibrium path. Group 3 contains many eastern European nations, Russia, China, as well as some African nations. During the sample period (1999-2013) the groups average GDP per capita increased by close to $600 \%$ from $\$ 1,320$ in 1999 to $\$ 7,671$ in 2013. Group 4 contains many Latin American, African and Middle-East nations.

Table 3 also denotes the breakdown of exchange-rate regime classifications by group (IMF classification). While there is some variation between groupings, exchange-rate regime does not appear to be a determining factor in group classification. Group 2, containing the majority of developed nations, has countries which would not often be associated in this category (for example, the inclu- 
sion of many African nations). ${ }^{7}$ As Bonhomme and Manresa (2015) note these groups are derived from the data and not through any modeling assumptions. A visual illustration of group assignment may lead the reader to believe the opposite. Groups are often clustered, but this is a result of countries in geographic proximity sharing similar economic attributes. The impact of countries sharing attributes is that errors tend to be spatially correlated. A geographic representation of groups is presented in Figure 4.

Figure 4: Geographic depiction of groups

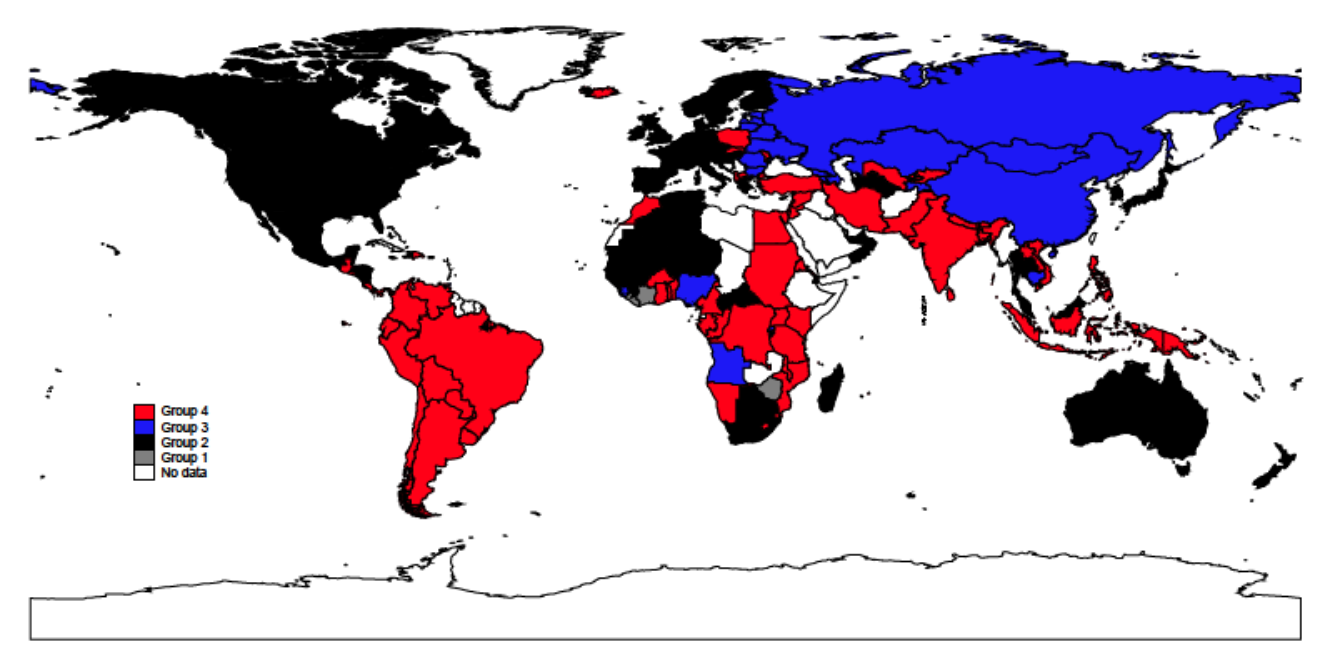

\subsection{Robustness checks}

To validate the estimates obtained in Section 5.1 a variety of sensitivity checks are necessary. The analysis first applies a two-staged least squares methodology to dispel any endogeneity concerns. Second, I apply an two alternate de facto exchange-rate regime classification via Shambaugh (2004) and Bayoumi and Eichengreen (1998). Third, I add additional control variables to see ensure that omitted variables did not contribute to the estimation, specifically measures for currency crises, banking crises, and capital controls. Fourth, I ensure the parameters are not the result of short-run fluctuations by averaging the data over 3 year intervals. Fifth, I test an alternate model specification which allows for time-invariant unit heterogeneity and group time-varying heterogeneity. Finally, I disaggregate the sample based on level of development in an attempt to view if income levels result in parameter heterogeneity. As a note, the grouped patterns of heterogeneity calculated in Section 5.1 are used in all robustness check results.

\footnotetext{
${ }^{7}$ Group classification by country is provided in Table 12
} 
To ensure that causality of the results goes from exchange-rate regime to economic growth this paper employs a two-staged least squares methodology. Following Ghosh (2014) I use a system GMM approach that uses lags of other explanatory variables as instruments. I consider regime dummies, trade openness, and years of secondary education as predetermined. All other explanatory variables are treated as endogenous. The results are reported in Regression (2). Intermediate and flexible exchange-rate regime takes the predicted sign, however, are statistically insignificant. Concerns surrounding endogeneity in this context may be overstated. The traditional argument that slow growth and rising unemployment will make it more difficult for countries to raise interest rates to defend their peg indicates, that if any bias exists, it is in the positive direction of intermediate and flexible exchange-rate regimes (Eichengreen and Leblang, 2003).

Using an two alternate de facto exchange-rate regime classifications, I test whether more flexible exchange-rate regimes are growth promoting. Shambaugh (2004) classifies exchange-rate regimes by determining whether they stayed within a +/- 2 percent band of a base currency; checking all major currencies internationally and locally important currencies (historically, many classifications assumed that the U.S. dollar was the base currency). To avoid spurious classification of pegs due to random lack of volatility, the de facto classification requires that countries be pegged for 2 consecutive years prior before being classified a peg. The classification has only two outcomes; peg or non-peg. We are thus testing the hypothesis of whether pegged exchange-rate regimes promote or hamper economic growth. The results for this are reported in Regression (3). The results show that non-pegs are growth promoting relative to pegs and these results are significant at the 5\% level. Covariate slope parameter estimates are similar to initial results with investment, trade and $\log$ of population having a positive effect on economic growth, significant at the $1 \%$ level. Population growth, life expectancy and education have growth hampering effects significant at the $5 \%$ and $10 \%$ levels; while government expenditure and terms of trade have negative slope parameter estimates but are statistically insignificant. While we are not able to test the hypothesis surrounding the differences between intermediate and flexible exchange-rate regimes, Shambaugh (2004) allows us to reduce the uncertainty regarding misclassification. A second de facto exchange-rate regime classification is used via Bayoumi and Eichengreen (1998) (see Equation 1 for a mathematical representation). Using percentage changes in exchange-rate and foreign exchange reserves I create an index between zero and one, with a higher value denoting a greater degree of exchange-rate flexibility. Estimated covariates take similar signs to initial estimates: investment, trade and population size having significant growth enhancing effects, while government expenditure and population growth have significantly negative growth hampering effects (see Regression (4)). The index slope parameter estimate is significant and negative, suggesting that countries with greater exchange-rate flexibility 
achieve lower growth rates. The contradictory nature of result should be approached with caution; a fundamental issue with indexes using foreign exchange reserve changes is that the change is biased by the stock of reserves (i.e. given the same absolute change, a country with a large stock of reserves will exhibit a lower percentage change than a nation with a small stock of reserves).

Section 2 stressed the importance of controlling for macroeconomic events that may have drastic growth implications that are indirectly related to exchange-rate regime. These include currency crises and banking crises, which have been readily apparent in the most recent financial turmoil. Following Frankel and Rose (1996) I classify a currency crisis as at least a 25\% nominal depreciation of a country's currency relative to the U.S. dollar, that is $10 \%$ higher than the currency depreciation in the previous time period. If a country meets the standard for a currency crisis multiple years in a row, I use the first year of a 3-year window to identify the crisis. Following Ghosh (2014) I classify a binary variable for banking crisis equal to 1 if the share of non-performing loans to total loans exceeds 10\%; Regression (5) reports the results when banking and currency crises variables are included in the regression. ${ }^{8}$ Both currency crises and banking crises exhibit a negative impact on economic growth, as the literature would suggest, with currency crises being significant at the $10 \%$ level and banking crises being significant at the $5 \%$ level. Results show that when controlling for currency crises, intermediate and fixed-exchange rates are growth promoting and significant at the $1 \%$ level. As Cecchetti, Kohler and Upper (2009) notes, when these crises occur together the impact on the economy may be more severe. To address these concerns Regression (6) classifies a twin crisis if both a banking crisis and currency crisis occur simultaneously. The slope parameter estimate for twin crises is negative, although insignificant. This result may arise from the definition of the currency crisis variable which limits the amount of twin crises in the dataset.

Capital controls can often cloud exchange-rate policy - for example, the decision to dismantle capital controls and adopt a flexible exchange-rate regime may be related (Eichengreen and Leblang, 2003). Following Miniane (2004) I compute a capital control index using de jure institutional information from AREAER. The paper assigns a value of one if controls are present and zero otherwise, for each of the 12 categories under capital transactions. ${ }^{9}$ These 12 categories are then averaged by country and year to compute the capital control index. A higher value of capital control index indicates a higher level of capital flow restriction. It is important to note that these de jure measures do not quantify the intensity of controls or whether they are enforced, only

\footnotetext{
${ }^{8} \mathrm{~A}$ non-performing loan is in default or close to being in default.

${ }^{9}$ The 12 categories include: controls on capital market securities, money market instruments, collective investment securities, derivatives and other securities, commercial credits, financial credits, guarantees; sureties; and financial backup facilities, controls on direct investment, liquidation of direct investment, real estate transactions, personal capital transactions, commercial banks and other credits institutions and controls on institutional investors.
} 
whether controls are present. Regression (7) show the results when accounting for capital flow restrictions - intermediate and flexible exchange-rate regimes are significant at the $1 \%$ level and growth promoting. A higher capital control index value has a negative slope parameter estimate, however it is statistically insignificant.

Averaging data has become a standard robustness check in empirical growth studies (see, e.g., Durlauf and Aghion (2014) pg. 625). Parameter estimates stand the risk of being contaminated by short-run fluctuations often associated with business cycle dynamics, by averaging the data we eliminate this potential source of bias. The mean of 3 -year intervals is used, changing $T=15 \rightarrow T=$ 5. Regression (11) reports the parameter estimates when $T$ is reduced to 5 , both intermediate and flexible exchange-rate regimes remain positive and are statistically significant at the $1 \%$ level. The remaining independent variables take similar slope parameter estimates to the original estimation; however, in this case government expenditure becomes statistically significant at the $1 \%$ level. This result acts a confirmation that the results derived under yearly time-dimensions are not driven by business cycle dynamics.

Using an alternate methodology I compute the GFE estimation in deviation to country-specific means. This specification can capture the time-invariant fixed-effects alongside grouped timevarying patterns of heterogeneity. Equation (8) shows the GFE model with unit-specific heterogeneity:

$$
\Delta y_{i t}^{p c}=\boldsymbol{\alpha}_{g(i), t}+\boldsymbol{\eta}_{i}+x_{i t}^{\prime} \boldsymbol{\theta}+\epsilon_{i t}
$$

Using this methodology we find similar results to those estimated above; intermediate and flexible exchange-rate regimes are growth promoting and significant at the $1 \%$ level. These results are reported in Regression (12).

Next, I examine whether the fixed-effects slope parameter estimates are drastically different as a result of trade levels. I disaggregate the sample by average trade (sum of exports plus imports divided by GDP). The contradictory slope parameter estimates using fixed-effects and grouped fixed-effects is the defining result of this thesis; this sensitivity analysis attempts to determine if these results were bias due to heterogeneous effects of exchange-rate regime based on level of trade. I classify low trade as an average trade level of below $75 \%$, medium trade as a level of $75 \%$ to $100 \%$, and high trade as a level of greater than $100 \%$. I report the slope parameter estimates for exchange-rate regime below.

When disaggregating the sample by level of trade, few of the exchange-rate regime slope param- 
Table 4: Exchange-rate regime estimates by level of trade

\begin{tabular}{l|ccc} 
Slope parameter estimate & Low trade & Middle trade & High trade \\
\hline \hline Intermediate exchange-rate regime & -0.509 & -0.642 & -0.675 \\
Flexible exchange-rate regime & $-0.827^{*}$ & -0.786 & $-1.044^{*}$ \\
\hline \hline $\mathrm{N}$ & 1,007 & 472 & 586 \\
$R^{2}$ & 0.40 & 0.53 & 0.4895
\end{tabular}

Note: ${ }^{*},{ }^{* *},{ }^{* *}$ indicates that the slope parameter is statistically significant at the $10 \%, 5 \%$ and $1 \%$ level.

eters are significant, even though they take similar signs to estimates of the full sample when using two-way fixed-effects. This sensitivity check highlights a fundamental issue with using fixed-effects on exchange-rate regime analysis. To capture unit-specific heterogeneity, the method must rely on within variation to produce parameter estimates. Countries do not often alter their exchange-rate regimes. By cutting the sample and using fixed-effects we are further limiting the within variation. Fixed-effects requires large $N$ and significant variation within units to produce consistent estimates, a problematic assumption in this thesis.

Finally, I disaggregate the sample by level of development. ${ }^{10}$ The implication of this diagnostic check is to investigate whether parameter heterogeneity is present across levels of development. For economies that are less developed, the ability to insulate from external shocks may be of less importance relative to more advanced economies.

Table 5: Exchange-rate regime estimates by level of development

\begin{tabular}{l|ccc} 
Slope parameter estimate & Low-income & Mid-income & High-income \\
\hline \hline Intermediate exchange-rate regime & 0.195 & $1^{* *}$ & 0.613 \\
Flexible exchange-rate regime & -0.097 & $0.799^{* * *}$ & 0.283 \\
\hline \hline $\mathrm{N}$ & 567 & 975 & 519 \\
$R^{2}$ & 0.46 & 0.5 & 0.71
\end{tabular}

Note: ${ }^{*}, * * * * *$ indicates that the slope parameter is statistically significant at the $10 \%, 5 \%$ and $1 \%$ level. Results for other slope parameters are reported in Regressions 8, 9, 10 .

These results may suggest that exchange-rate regime is most important for emerging/ middleincome countries and by adopting intermediate or flexible exchange-rate regimes these countries can obtain higher economic growth. However, these results should be approached with caution as we

\footnotetext{
${ }^{10}$ We classify level of development by GNI per capita in 1999 using the thresholds defined by World Bank Atlas Method in Table 3
} 
are unable to determine whether these results are driven from a sample bias given the low amount of observations.

\section{Conclusion}

This thesis examines the impact of exchange-rate regime on economic growth using panel data for 151 countries over the period 1999-2013. I find that countries pursuing more flexible exchangerate regimes experience higher economic growth relative to their counterparts. This paper benefits from advancements in transparency of exchange-rate regime classification through the AERARE transition from de jure to de facto classification. These results hold across different exchange-rate classification methods, additional controls, and methodology specifications. This paper offers three concluding remarks.

First, contrary to predictions following the exchange-rate crises of the 1990's, I do not see a "disappearance of the middle" (see, e.g., Summers (1999) ; Eichengreen (1994) ; Eichengreen (1998)). This hypothesis was based on the increasingly integrated financial markets around the world. The impossible trinity states that exchange-rate stability, monetary independence and free capital flows are mutually incompatible. The integration of financial markets - leading to capital flow - was thought to force nations to choose between exchange-rate stability and monetary independence (Frankel, 1999). The breakdown of exchange-rate regime confirms that we do not see this result. Unfortunately, quantifying this result is problematic; the alteration of the AERARE classifications in 2008 undoubtedly caused a shift in the exchange-rate regime status (see Table 7). Nonetheless, we can conclude that there is not a disappearing of the middle as was hypothesized.

Second, the paper has highlighted the importance of capturing time-varying heterogeneity. Not accounting for these effects in a flexible manner has serious implications for slope parameter estimates - as highlighted by the contradictory results using a two-way fixed-effects model in Section 5.1. Using the grouped fixed-effects estimator, I find that intermediate and flexible exchange-rate regimes are significant growth promoters, while the two-way fixed-effects model suggests that both intermediate and flexible exchange-rate regimes have a significant growth hampering impact. The two-way fixed-effect model captures unit-specific heterogeneity, but is relatively poor in the context of time-varying heterogeneity. This thesis argues that, whilst examining the impact of exchangerate regime on economic growth, a model capturing different patterns of time-varying heterogeneity is a better fit for the data. This result is confirmed by the value of objective functions reported in Table 6. The focus of time-varying heterogeneity in this paper has concentrated on speed of adjustment effects - the ability for less developed economies to grow at higher rates via the adoption 
of technology, laws, economic policy, economic structure et cetera. But, the flexibility of this approach allows the model to capture many other unobserved effects that may be region specific (wars, famine, natural disasters, and so forth). The model may also capture parameter heterogeneity for example, investment may have a more significant impact on economic growth in countries with relatively lower levels of development. Ultimately, the GFE offers a parsimonious approach to capturing unobserved heterogeneity, specifically time-varying heterogeneity. The restrictions placed by a two-way fixed-effects model on capturing this time component appear to be a problematic assumption in a heterogeneous sample examining economic growth.

Finally, the policy implications of these results should be approached with some caution. This is not a suggestion that countries massively adopt flexible exchange-rate regimes. As Section 1 highlighted, the theoretical consensus for the impact of exchange-rate regime on economic growth remains ambiguous. Under the view of the natural-rate hypothesis, monetary independence should have no impact on long-run growth. This may suggest that the results merely capture short-run recovery, or that the results are spurious in nature. In this case, sample selection may be the driving force behind the results. Under a New-Keynesian view, these results may suggest that countercyclical monetary policy allowed countries to achieve higher growth rates by reducing the effect of external shocks, namely the Great Recession. The theoretical implications of the NK model suggest that monetary policy can keep incentive for investment from falling during and after recessions. Given the importance of investment via slope parameter estimates, increasing investment would be of utmost importance following the financial crisis, as investment across all groups suffered greatly (see Figure 3). If we impose the assumption of asymmetric shocks, the results in Regression (9) may suggest that the ability to mitigate external shocks are most important to developing economies. Speed of adjustment to new long-run equilibrium would imply that these economies have the most to lose with regards to recessions and a stagnating economy. However, adoption of these intermediate and flexible exchange-rate regimes for developing economies may require a minimum level of financial sector development to conduct open market operations (Ghosh, 2014). Tools such as forward exchange markets may be necessary to eliminate exchange-rate volatility, which may hinder foreign investment and trade. Nonetheless, I leave these questions for future research.

What may be understated in this thesis, and prior investigations into the impact of exchangerate regime on economic growth, is that there does not exist a universal optimal exchange-rate regime. Country characteristics may dictate the optimal exchange-rate regime; for example, countries with internal troubles, such as excessive inflation, may choose to peg their exchange-rate in an effort to import inflation-fighting credibility. Countries subject to many external disturbances, 
such as foreign demand for domestic products, may find the benefits flexible exchange-rate the most beneficial. This thesis has examined the empirical relationship between exchange-rate regimes and economic growth, but does not attempt to address the question of what exchange-rate regime is optimal given country specifics (indeed, "optimum currency areas" is a large section of literature dedicated to this type of question).

Future research on the impact of exchange-rate regimes should aim to go beyond the specificity in this paper, and in the existing literature. As highlighted by Rose (2011), fixed exchange-rate policy is well understood, flexible exchange-rate policy is much less so. Some countries inflation target, some target money growth, others are indistinguishable; the ambiguity of results may be driven by attempting to classify non-fixes in the same category, even though they may be pursuing drastically different policy positions. Considering monetary policy framework, instead of exchangerate regime, may be a solution to this problem. Analogously, future research may benefit from classifying what currency pegged exchange-rate regimes are fixed to, since pegged exchange-rate regimes may inextricably link economies business cycles.

This thesis is as an empirical approach to the impact of exchange-rate regime on economic growth. I do not attempt to address which view is correct, rather to set a benchmark for future research, with respect to methodology and time-frame. Due to the uncertainty surrounding exchange-rate regime classification (prior to the time frame used in this paper) extending the sample period backwards is not a viable option. Continuing to examine economies will hopefully lead to a consensus on the impact of exchange-rate regime for economic growth, and whether their exists long-run impacts of independent monetary policy. Ultimately, the research in this area must reconcile differences between theoretical hypotheses and empirical data to come to a firm consensus on this topic. 


\section{References}

Acemoglu, D., Johnson, S., Robinson, J., And Thaicharoen, Y. (2003): "Institutional causes, macroeconomic symptoms: volatility, crises and growth", Journal of Monetary Economics, Vol. 50, No.1, pp. 49-123.

Alexiadis, S. And Tomkins, J. (2010): "Technology adoption and club convergence", MPRA Working Paper No. 21137.

Andrade, M., Madalozzo, R., and Vallas Pereira, P. L. (2004): "Convergence clubs among Brazilian municipalities", Economic Letters, 83, 179-184.

Bailliu, J., Lafrance, R. And Perrault, J. (2003): "Does Exchange Rate Policy Matter for Growth?", International Finance, 6(3), 381-414.

BALL, L. (2014): "Long-term damage from the Great Recession in OECD countries", NBER Working Paper, No. 20185, May.

Bandyopadhyay, S. (2011): "Convergence Clubs Empirics: Evidence from India States".

Bayoumi, T. And Eichengreen, B. (1998): "Exchange Rate Volatility and Intervention: Implications of the Theory of Optimal Currency Areas," Journal of International Economics, 45(2), 191-209.

Blanchard, O., And Summers, L. (1986): "Hysteresis and the European Unemployment Problem," NBER Macroeconomics Annual, 1, 15-90.

Blanchard, O., And Wolfers, J. (1987): "Hysteresis in Unemployment," European Economic Review, 31, 288-295.

Bleaney, M., And Francisco, M. (2007): "Exchange Rate Regime, Inflation and Growth in Developing Economies - An Assessment," The BE Journal of Macroeconomics, 7(1), 1-18.

Bleaney, M. AND M. Tian (2014): "Classifying exchange rate regimes by regression methods," The University of Nottingham Discussion Papers in Economics, No. 14/02

Bonhomme, S. And Manresa, E. (2015): "Grouped Patterns of Heterogeneity in Panel Data," Econometrica, 83(3), 1147-1184.

Brusco, M.J. And D. Steinley (2007): "A Comparison of Heuristic Procedures for Minimum Within-Cluster Sum of Squares Partitioning," Psychometrika, 72(4), 583-600.

Calvo, G.A. (1999): "Fixed versus Flexible Exchange Rates: Preliminaries of Turn-of-Millennium Rematch". Unpublished manuscript.

Calvo, G.A. And Reinhart, C.M. (2002): "Fear of Floating," Quarterly Journal of Economics, 117, 379-408. 
Canova, F. (2004): "Testing for Convergence Clubs in Income Per Capita: A Predictive Density Approach", International Economic Review, 45(1), 49-77.

Cecchetti, S., Kohler, M., And Upper, C. (2009): "Financial Crises and Economic Activity", Federal Reserve Bank of Kansas.

Contessi, S., And El-Ghazaly, H. (2011): "Banking Crisis around the World, Different Governments, Different Responses", The Federal Reserve Bank of St. Louis..

Cordero, J. A., And Mentecino, J. A. (2010): "Capital Controls and Monetary Policy in Developing Countries", Center for Economic and Policy Research Working Paper.

De Grauwe, P. And Schnabl, G. (2008): "Exchange Rate Stability, Inflation, and Growth in (South) Eastern and Central Europe", Review of Development Economics, 12(3), 530-549.

Dehejia, V. H., And Rowe, N. (1998): "The Effect of Business Cycles on Growth: Keynes vs. Schumpeter", Economic Inquiry, 36(3), 501-511.

De Vita, G. And K. Kyaw (2011): "Does the Choice of Exchange Rate Regime Affect the Economic Growth of Developing Countries?" The Journal of Developing Area, 45, 135-153.

Dornbusch, R. (2001): "Fewer Monies Better Monies, Discussion on Exchange Rates and the Choice of Monetary-Policy Regimes", American Economic Review, 91(2), 238-242.

Dubas, J.M., Lee, J. And Mark, N.C. (2005): "Effective Exchange Rate Classifications and Growth", NBER Working Paper, No. 11272

Durlauf, S. N., P. A. Johnson and J. R. Temple(2005): "Growth econometrics" in Handbook of Economic Growth, ed. by P. Aghion and S. N. Durlauf, vol. 1A, pp. 555-677, Amsterdam. North Holland.

Durlauf, S. N. And P., Aghion(2014): Handbook of Economic Growth. Elsevier B.V., second edn.

Eichengreen, B. (1994): International Monetary Arrangements for the 21st Century, Brookings Institution, Washington DC.

Eichengreen, B. (1998): "The Only Game in Town," UC Berkeley, November.

Eichengreen, B. And Leblang, D. (2003): "Exchange Rates and Cohesion: Historical Perspectives and Poltical-Economy Considerations," Journal of Common Market Studies, 41(5), 797-822.

Eichengreen, B. And Razo-Garcia, R. (2011): "How Reliable are De Facto Exchange Rate Regime Classifications?", NBER Working Paper No. 17318. JEL No. F0,F31.

Fatas, A. And Minov, I.(2013):"From recession to normalcy: Recoveries as a third phase of the business cycle", CEPR discussion paper, No. 9551. 
Fischer, S. (2001): "Exchange Rate Regimes: Is the Bipolar View Correct?" Journal of Economic Perspectives, 15, 3-24.

FoAd, H. S. (2005): "Exchange Rate Volatility and Export Oriented FDI", Emory University, pp. $2-7$.

Forgy, E. W. (1965): "Cluster Analysis of Multivariate Data: Efficiency vs. Interpretability of Classifications", Biometrics, 21, 768-769.

FrANKEL, J. (1999): "No single currency regime is right for all countries or at all times," NBER Working Paper No. 7338.

Frankel, J. And Rose, A. (1996): "Currency Crashes in Emerging Markets: An Empirical Treatment," International Finance Discussion Papers, 534.

Frankel, J. And Rose, A. (2002): "An Estimate of the Effect of Common Currencies on Trade and Income," Quarterly Journal of Economics, 117, 437-466.

Frankel, J. And Wei, S.J. (1993): "Trade and Currency Blocs," NBER Working Paper No. 4335.

Friedman, M. (1953): "The Case for Flexible Exchange Rates," Essays of Positive Economics. University of Chicago Press.

Friedman, M. (1968): "The Role of Monetary Policy," The American Economic Review. Volume LVII, Number 1.

Gali, J. (2015): "Hysteresis and the European Unemployment Problem Revisited", CREI Working Paper.

Grosh, A. (2014): "Do Exchange Rate Regimes Matter for Economic Growth?", Journal of Internation Economics / Economia Internazionale, 67(3), 351-372.

Ghosh, A., Gulde, A-M., Wolf, H. (2002): "Exchange Rate Regimes: Choices and Consequences", MIT Press.

Ghosh, A.R., Ostry, J.D., Gulde, A.M. And Wolf, H.C. (1997): "Does the Exchange Rate Regime Matter for Inflation and Growth?", IMF Econoimic Issues, 2, 1-19.

Grunewald, N., Klasen, S., Martinez-Zarzoso, I. And Muris, C. (2015): "The Trade-off Between Income Inequality and Carbon Dioxide Emissions".

Habermeier, K., Kokenyne, A., Veyrune, R. and Anderson, H. (2009): "Revised System for the Classification of Exchange Rate Arrangements". IMF Working Paper.

Hahn, J., And W. Newey (2004): "Jackknife and Analytical Bias Reduction for Nonlinear Panel Models, "Econometrica, 72, 1295-1319 
Hansen, P., And Mladenovic, N. (1997): "Variable neighborhood nearch", Computers and Operations Research, 24(11), 1097-1100.

Hansen, P., And Mladenovic, N. (1998): "“An Introduction to Variable Neighborhood Search", In S. Voss et al. (eds.), Metaheuristics, Advances and Trends in Local Search Paradigms for Optimization, 433-458.

Hansen, P., And Mladenovic, N. (2001): "J-Means: A New Local Search Heuristic for Minimum Sum-of-Squares Clustering", Pattern Recognitiion, 34(2), 405-413.

Ilzetzki, E., Reinhart, C. M., And Rogoff, K. S. (2010): "Exchange Rate Arrangements Entering the 21st Century: Which Anchor Will Hold?"

Lee, K. C., M. H. Pesaran, and R. P. Smith (1997): "Growth and Convergence in a Multicountry Empirical Stochastic Solow Model", Journal of Applied Econometrics, 12, 357-392.

Levy-Yeyati, E. And Sturznegger, F. (2002): "To Float or to Fix: Evidence on the Impact of Exchange Rate Regimes on Growth," American Economic Review, 12(2), 1-49.

Lin, C. And NG, S. (2012): "Estimation of Panel Data Models with Parameter Heterogeneity when Group Membership is Unknown", Journal of Econometric Methods, 1(1), 42-55.

Massoumi, E. And Wang, L. (2008): "Economic reform, growth and convergence in China", Econometrics Journal, 11, 128-154.

Miles, W. (2006): "To Float or not to Float? Currency Regimes and Growth," Journal of Economic Development, 31(2), 91-105.

Miles, W. (2008): "Exchange rates, inflation and growth in small, open economices: a differencein-differences approach," Applied Economics, 40, 341-348.

Miniane, J.(2004): "A New Set of Measures on Capital Account Restrictions", IMF Staff Papers, $51(2)$.

Moreno, R. (2000): "Pegging and Macroeconomic Performance in East Asia," ASEAN Economic Bulletin, 18(1), 48-63.

Moreno, R. (2001): "Pegging and Stabilization Policy in Developing Countries," Economic Review of the Federal Reserve Bank of San Francisco, 12(99), 17-29.

Nickel, S. (1981): "Biases in Dynamic Models with Fixed Effects," Econometrica, 49, 1417-1426.

Pacheco, M. And O. Valencia (2003): "Design of hybrids for the minimum sum-of-squares clustering problem," Computational Statistics and Data Analysis, 43(2), 235-248.

PATREski, M. (2009): "Exchange-rate regime and economic growth: a review of the theoretical and empirical literature," Economics / Discussion papers, No. 2009-31 
Phillips, P. C. B., And Sul, D.(2007): "Transition Modelling and Econometric Convergence Tests", Econometrica, 75, 1771-1855.

Rose, A.(2011): "Exchange Rate Regimes in the Modern Era: Fixed, Floating, and Flaky," Journal of Economic Literature, 49(3): 652-72.

Schnabl, G.(2007): "Exchange Rate Volatility and Growth in Emerging Europe and East Asia", CESifo Working Paper No. 2023.

Shambaugh, J.(2004): "The Effect of Fixed Exchange Rates on Monetary Policy," Quarterly Journal of Economics

Shambaugh, J. And Klein, M.(2004): "Fixed Exchange Rates and Trade," NBER Working Paper No. 10696.

Summers, L.(1999): testimony before the Senate Foreign Relations Subcommittee on International Economic Policy and Export/Trade Promotion, January 27.

Vogel, J.(2013): "Regional Convergence in Europe: A Dynamic Heterogenous Panel Approach", Austrian Institute of Economic Research working paper. 


\section{Appendix A}

Table 6: GFE estimates

\begin{tabular}{|c|c|c|c|c|c|}
\hline G & Obj. Fn. & BIC & $\begin{array}{c}\text { Intermediate parameter } \\
\left(\delta_{9}\right)\end{array}$ & $\begin{array}{c}\text { Flexible Parameter } \\
\left(\delta_{10}\right)\end{array}$ & $R^{2}$ \\
\hline$\overline{11}$ & $\overline{30,280.12}$ & 15.09 & {$[0.4499 .12 * 4599]$} & {$\left[-0.0261^{386}, 0.7430\right]$} & 0.2642 \\
\hline 2 & $23,585.03$ & 13.62 & {$[-0.3630,0.86663]$} & {$[-0.2995,0.5409]$} & 0.3758 \\
\hline 3 & $21,323.85$ & 12.88 & {$[0.1625,0.9076]$} & {$[0.1625,0.9076]$} & 0.4356 \\
\hline 4 & $19,413.35$ & 12.29 & {$[0.4137,1.5903]$} & {$[0.2112,0.9840]$} & 0.4862 \\
\hline 5 & $17,600.16$ & 11.74 & {$[0.5075,1.6652]$} & {$[0.2882,1.0616]$} & 0.5342 \\
\hline 6 & $16,084.18$ & 11.32 & {$[-0.1270,0.8598]$} & {$\left[-0.1422^{633}, 0.6839\right]$} & 0.5743 \\
\hline 7 & $14,941.51$ & 11.07 & {$[0.5381,1.5054]$} & {$[0.3711,1.1166]$} & 0.6045 \\
\hline 8 & $13,777.70$ & 10.81 & {$[0.6132,1.5684]$} & {$[0.3457, \stackrel{0}{1.0718}]$} & 0.6353 \\
\hline 9 & $12,845.54$ & 10.65 & {$[0.4271,1.16 * * 639]$} & {$[0.1755,0.8173]$} & 0.6600 \\
\hline 10 & $12,020.66$ & 10.54 & {$[0.4150,1.1711]$} & {$[0.1266,0.7675]$} & 0.6818 \\
\hline 11 & $11,244.99$ & 10.45 & {$[0.5583,1.3095]$} & {$[0.2656,0.9596]$} & 0.7024 \\
\hline 12 & $10,653.58$ & 10.44 & {$[0.5119,1.1933]$} & {$[0.2455,0.8525]$} & 0.7180 \\
\hline 13 & $10,157.32$ & 10.47 & {$[0.5594,1.2742]$} & {$\left[0.06^{2} 77^{398 *}, 0.7280\right]$} & 0.7312 \\
\hline 14 & $9,688.38$ & 10.52 & {$[0.4963,1.2417]$} & {$[0.3173,0.9243]$} & 0.7437 \\
\hline 15 & $9,263.41$ & 10.58 & {$[0.3747,1.1488]$} & {$[0.1957,0.8114]$} & 0.7550 \\
\hline $\mathrm{FE}$ & $21,184.62$ & & $\begin{array}{c}-0.892^{* *} \\
{[-1.6209,-0.1628]}\end{array}$ & $\begin{array}{c}-0.976 * * * \\
{[-1.6210,-0.3308]}\end{array}$ & 0.4393 \\
\hline
\end{tabular}

Note: In calculating $\hat{\sigma}^{2}$ we set $G_{\max }=15$. Script-size numbers in square brackets denote the bounds of $95 \%$ confidence intervals. ${ }^{*}, * *, * * *$ indicates that the slope parameter is statistically significant at the $10 \%, 5 \%$ and $1 \%$ level. Results for the two-way fixed-effects regression are reported in regression 13.

Table 7: AREAER Exchange-rate distrubution by year

\begin{tabular}{|c|c|c|c|c|c|c|c|c|c|c|c|c|}
\hline \multirow[b]{2}{*}{ Year } & \multicolumn{3}{|c|}{ Full sample } & \multicolumn{3}{|c|}{ Low income } & \multicolumn{3}{|c|}{ Mid. Income } & \multicolumn{3}{|c|}{ High income } \\
\hline & Fix & Float & Interm. & Fix & Float & Interm. & Fix & Float & Interm. & Fix & Float & Interm. \\
\hline 1999 & 64 & 63 & 15 & 22 & 30 & 4 & 26 & 23 & 6 & 16 & 10 & 5 \\
\hline 2000 & 63 & 69 & 11 & 21 & 33 & 3 & 26 & 26 & 5 & 16 & 10 & 3 \\
\hline 2001 & 61 & 70 & 12 & 20 & 33 & 3 & 25 & 27 & 6 & 16 & 10 & 3 \\
\hline 2002 & 65 & 66 & 13 & 21 & 30 & 3 & 28 & 25 & 7 & 16 & 11 & 3 \\
\hline 2003 & 64 & 68 & 12 & 20 & 32 & 2 & 27 & 24 & 7 & 17 & 12 & 3 \\
\hline 2004 & 61 & 73 & 10 & 16 & 30 & 1 & 27 & 30 & 6 & 18 & 13 & 3 \\
\hline 2005 & 67 & 67 & 10 & 19 & 25 & 1 & 29 & 29 & 6 & 19 & 13 & 3 \\
\hline 2006 & 62 & 73 & 10 & 19 & 20 & 1 & 35 & 26 & 6 & 8 & 27 & 3 \\
\hline 2007 & 61 & 74 & 10 & 19 & 19 & 1 & 33 & 26 & 8 & 9 & 29 & 1 \\
\hline 2008 & 42 & 71 & 32 & 11 & 13 & 9 & 21 & 28 & 21 & 10 & 30 & 2 \\
\hline 2009 & 43 & 62 & 40 & 12 & 8 & 10 & 20 & 24 & 28 & 11 & 30 & 2 \\
\hline 2010 & 40 & 59 & 45 & 12 & 7 & 11 & 19 & 21 & 31 & 9 & 31 & 3 \\
\hline 2011 & 40 & 59 & 45 & 12 & 7 & 10 & 17 & 21 & 31 & 11 & 31 & 4 \\
\hline 2012 & 40 & 59 & 45 & 12 & 6 & 10 & 17 & 20 & 31 & 11 & 33 & 4 \\
\hline 2013 & 40 & 59 & 46 & 11 & 6 & 9 & 19 & 19 & 31 & 10 & 34 & 6 \\
\hline
\end{tabular}

Note: Country income classification is based upon gross national income per capita with boundaries set via World Bank Atlas Method. Countries with GNI less than $\$ 1,045$ are considered low-income; $\$ 1,046-\$ 12,735$ are considered middle-income; and countries with greater than $\$ 12,735$ are considered high-income countries. 
Table 8: Summary Statistics

\begin{tabular}{lrlrrrr}
\hline Variable & Source & Unit & Mean & Std. Dev. & Min & Max \\
\hline \hline $\begin{array}{l}\text { Dependent variable } \\
\text { GDP cap. growth }\end{array}$ & WDI & $\%$ & & & \\
& & 2.47 & 4.30 & -37.29 & 33.03 \\
\hline Controls & & & & & & \\
Govt. Expenditure & WDI & \% of GDP & 16.02 & 9.05 & 2.05 & 156.53 \\
Investment & WDI & $\%$ of GDP & 22.95 & 7.73 & 0.2928 & 67.91 \\
Trade & WDI & $\%$ of GDP & 88.54 & 53.17 & 18.76 & 455.28 \\
Population growth & WDI & $\%$ of population & 1.45 & 1.39 & -2.85 & 15.03 \\
Secondary schooling & WDI & years & 6.42 & 0.91 & 4 & 9 \\
Population & WDI & log scale & 16.04 & 1.65 & 12.10 & 21.03 \\
Terms of Trade & WDI & constant LCU & $5.53 \mathrm{e}+11$ & $1.22 \mathrm{e}+13$ & $-1.52 \mathrm{e}+14$ & $2.08 \mathrm{e}+14$ \\
Life Expectancy & WDI & years & 68.43 & 10.23 & 37.45 & 83.83 \\
\hline
\end{tabular}

Note: Summary statistics for balanced panel data set with 2,065 observations $(n=151, T \in 1999, \ldots, 2013)$.

Figure 5: Kernel density of GDP growth rates by year

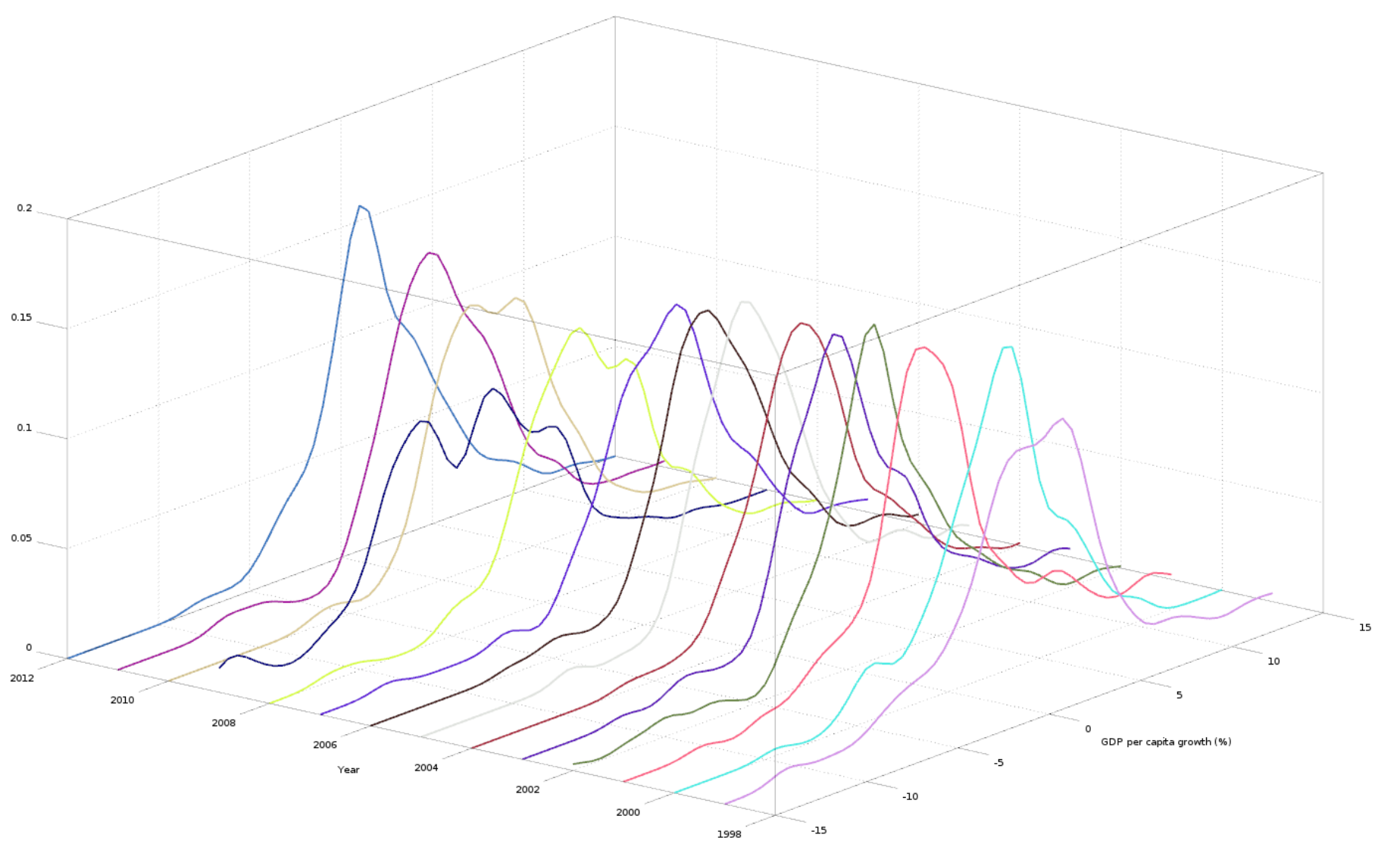

Note: The figure depicts distribution of growth rates by year. This figure highlights the significant impact of the Great Recession on output during 2008. All other years, the distribution of growth following an approximately normal. During 2008, the distribution appears much like a bimodal distribution, with many countries suffering significant negative growth rates. 
Figure 6: Objective function by number of groups

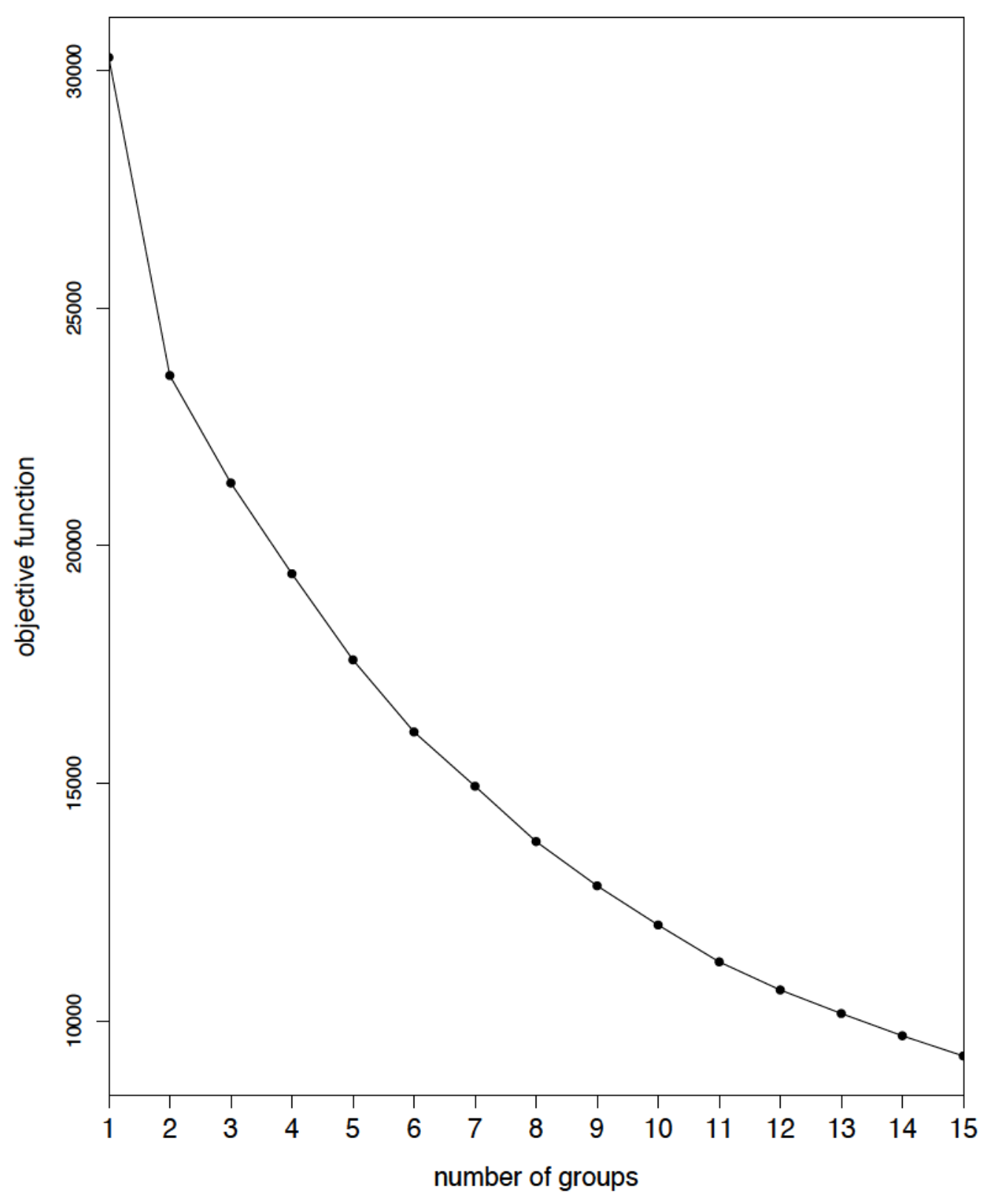




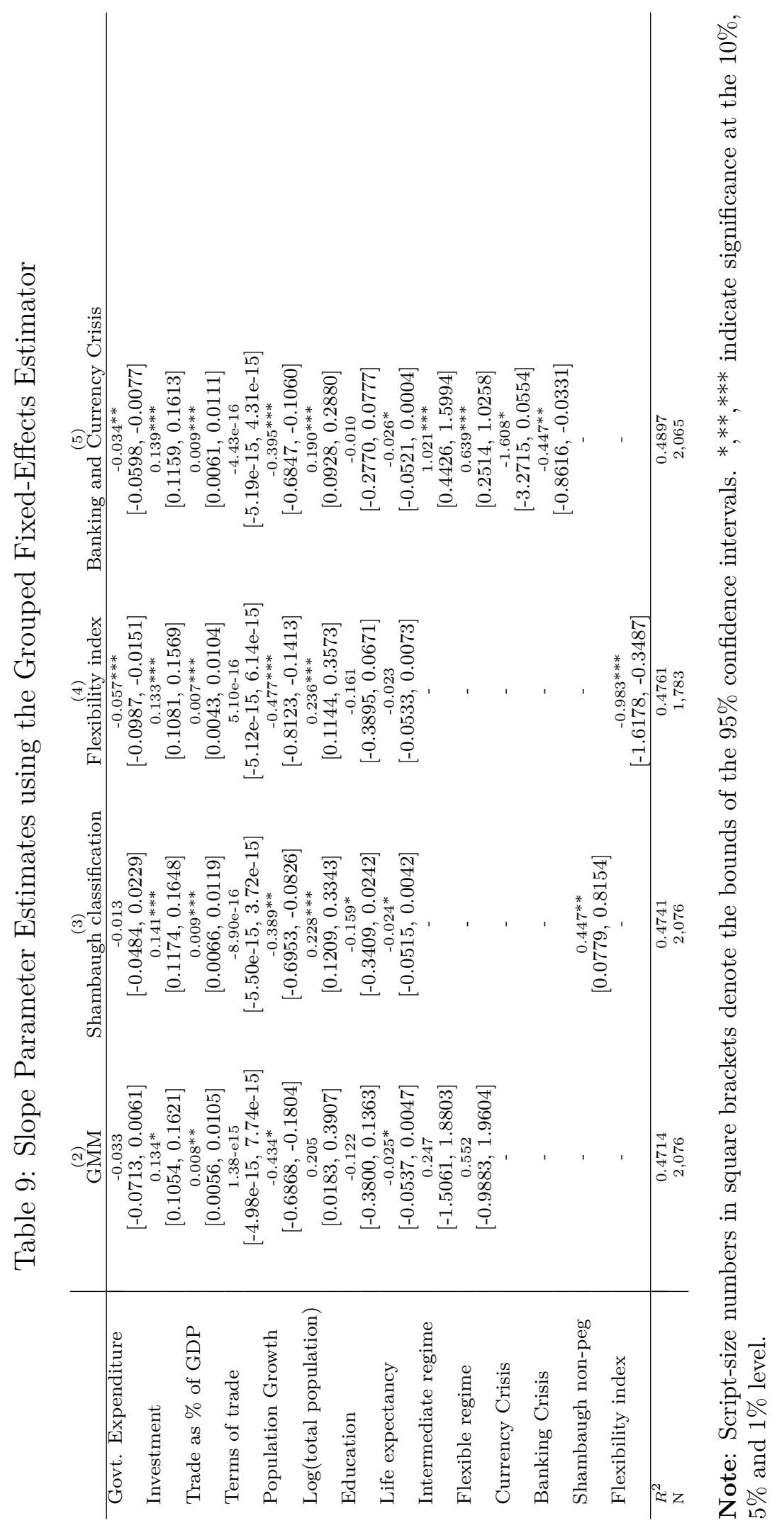




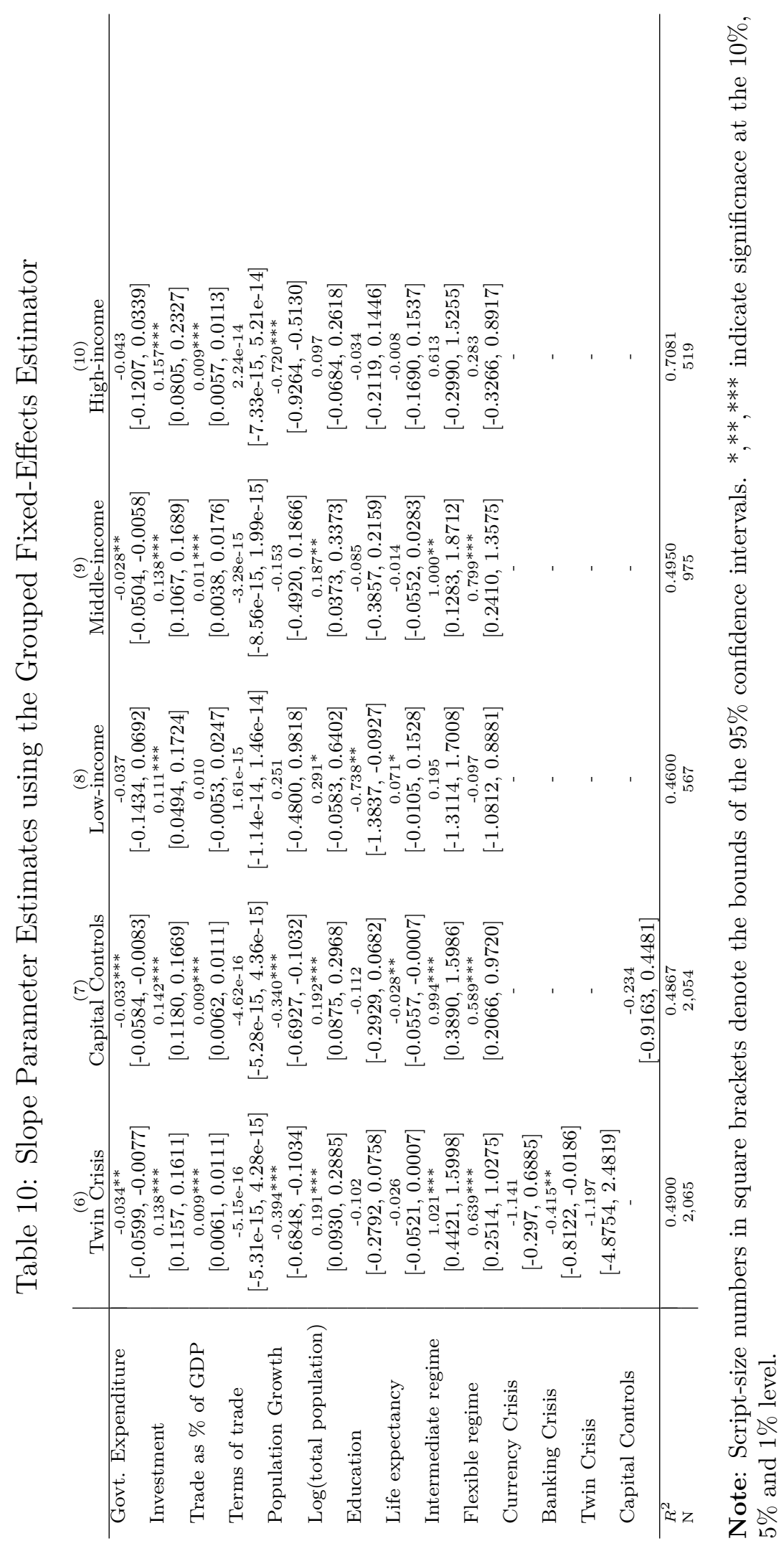




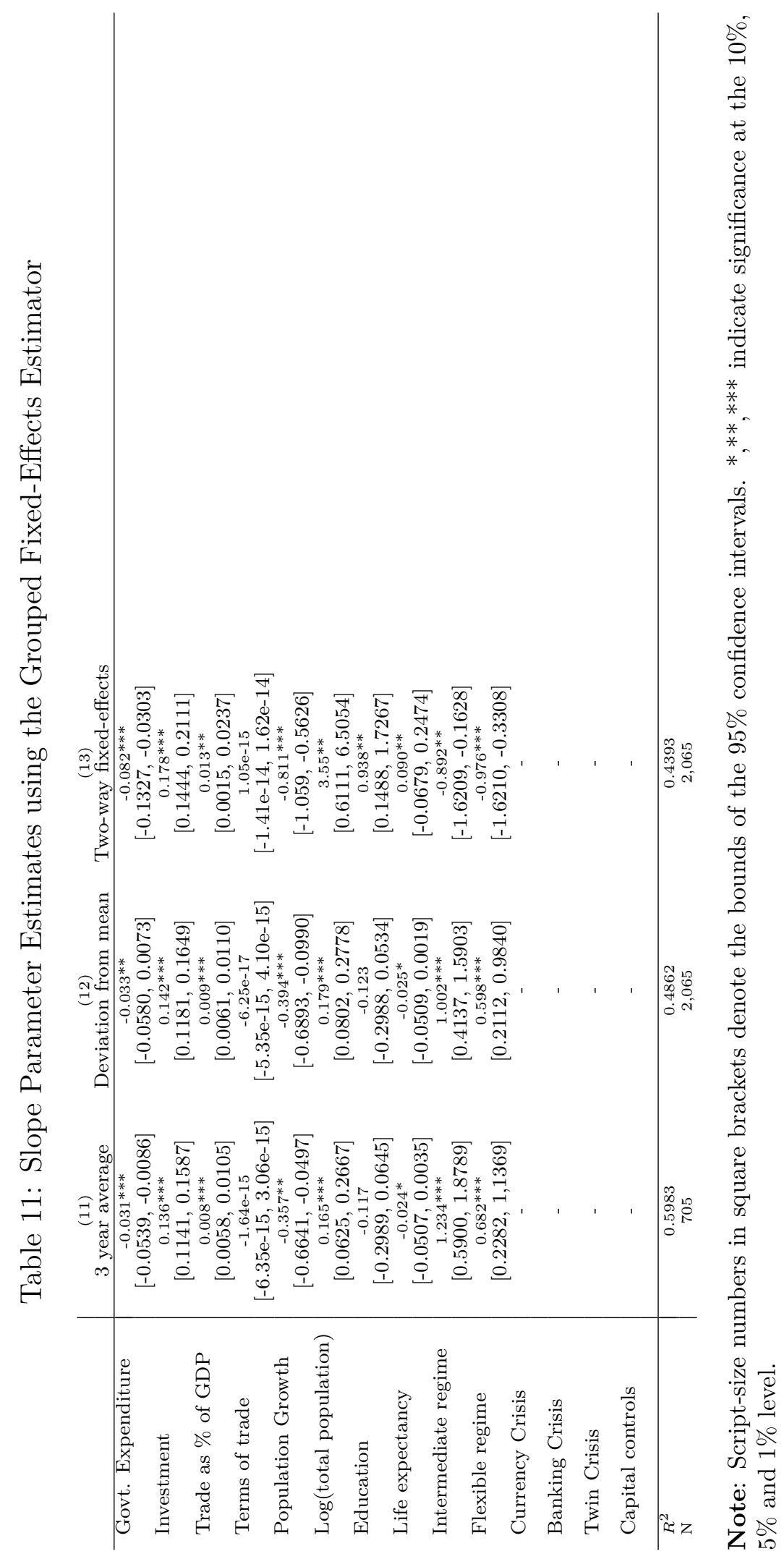


Table 12: Group Classification when $G=4$

Group 1: Cote d'Ivoire Liberia Zimbabwe

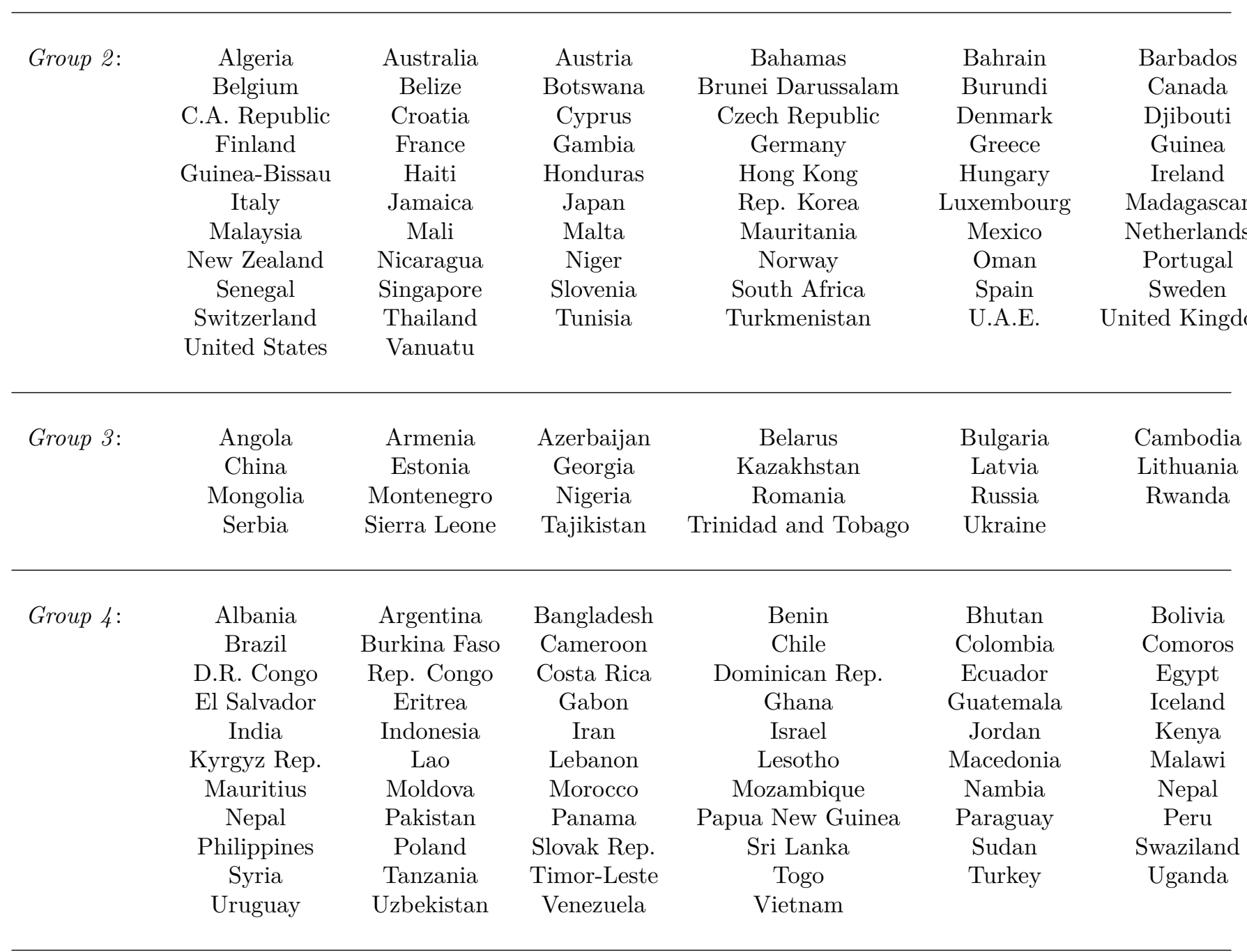




\section{Appendix B}

\section{B.1 Computation}

The computation of the grouped fixed-effects estimator offers a choice between two algorithms: Algorithm 1 is an iterative procedure which alternates between group classification (9) and estimation of the common parameters (10) until numerical convergence:

$$
\begin{gathered}
g_{i}^{(s+1)}=\underset{g \in\{1, \ldots, g\}}{\operatorname{argmin}} \sum_{t=1}^{T}\left(\Delta y_{i t}^{p c}-\boldsymbol{x}_{i t}^{\prime} \boldsymbol{\theta}^{(s)}-\boldsymbol{\alpha}_{g t}^{(s)}\right)^{2} \\
\left(\boldsymbol{\theta}^{(s+1)}, \boldsymbol{\alpha}^{(s+1)}\right)=\underset{(\boldsymbol{\theta}, \boldsymbol{\alpha}) \in \Theta \times A^{N T}}{\operatorname{argmin}} \sum_{t=1}^{T}\left(\Delta y_{i t}^{p c}-\boldsymbol{x}_{i t}^{\prime} \boldsymbol{\theta}^{(s)}-\boldsymbol{\alpha}_{g_{i}^{(s+1)} t}\right)^{2}
\end{gathered}
$$

For ease of exposition we define a general objective function in (11); using this objective function we describe Algorithm 1 below.

$$
F_{N, T}(\boldsymbol{\theta}, \boldsymbol{\alpha}, \boldsymbol{\gamma})=\sum_{i=1}^{N} \sum_{t=1}^{T}\left(\Delta y_{i t}^{p c}-\boldsymbol{x}_{i t}^{\prime} \boldsymbol{\theta}-\boldsymbol{\alpha}_{g_{i}}\right)^{2}
$$

Algorithm 1 below minimizes $F_{N, T}(\boldsymbol{\theta}, \boldsymbol{\alpha}, \gamma)$ over the domain $\Theta \times \mathcal{A}^{G T} \times \Gamma_{G}$ of $(\boldsymbol{\theta}, \boldsymbol{\alpha}, \gamma)$.

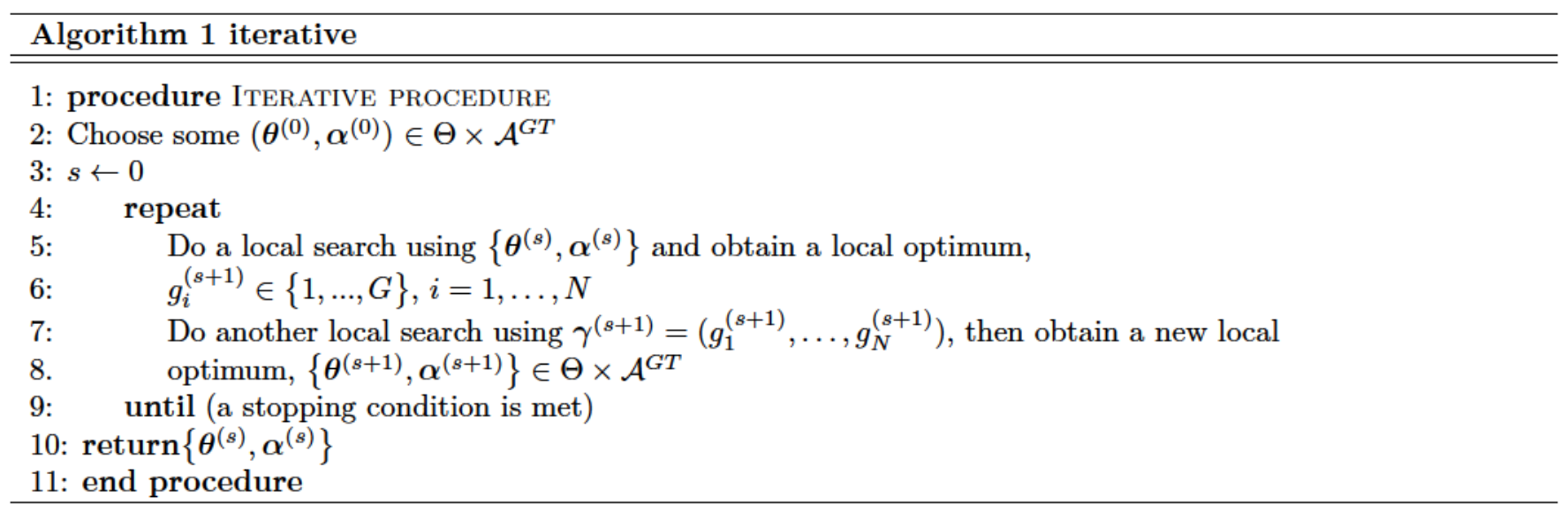

This clustering algorithm coincides with the well-known $k$-means algorithm, if $\theta=0$ (see Forgy (1965)). Algorithm 1 is fast in its numerical convergence, but a downside to the iterative procedure is 
its dependence on starting values. Choosing many random starting values is an informal solution to the problem, a more efficient approach is to draw $\theta^{(0)}$ from some pre-specified distribution supported on $\Theta$ (Bonhomme and Manresa, 2015).

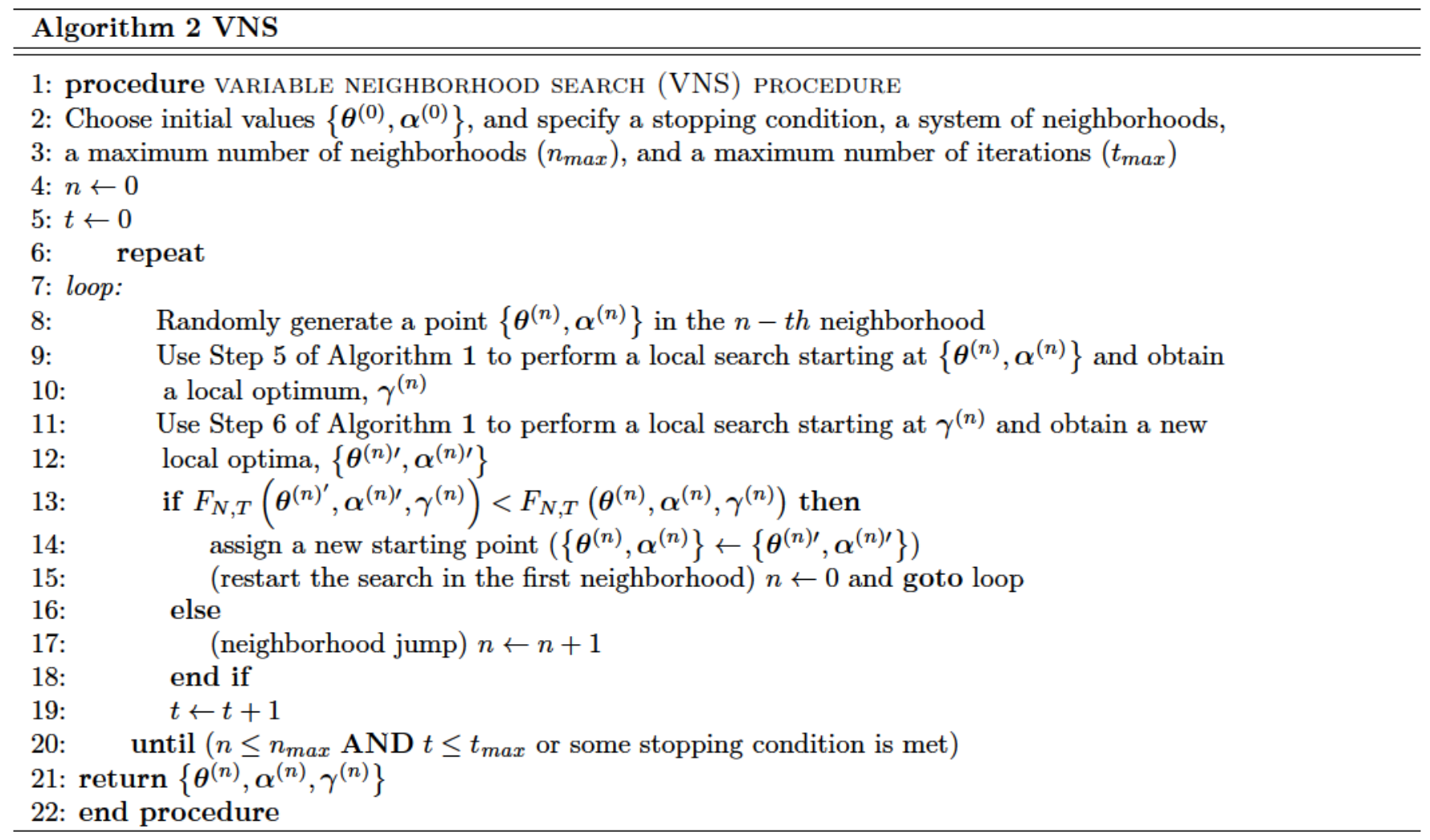

Algorithm 2 is a variable neighborhood search procedure, which is able to circumvent the issues presented in algorithm 1 regarding starting values. VNS is considered state-of-the-art in solving a set of combinatorial optimization and global optimization problems (for an introduction to such procedures see, Hansen and Mladenovic (1997); Hansen and Mladenovic (1998); Hansen and Mladenovic (2001)). The GFE VNS algorithm is an extension, with covariates, of algorithms described in Pacheco and Valencia (2003) and Brusco and Steinley (2007). VNS algorithms make use of local search procedures repeatedly. After obtaining initial grouping $\gamma$, VNS moves $n$ randomly selected units to $n$ randomly selected groups, if the objective function decreases as a result of the move then the new grouping is now $\gamma$. This random reassignment exploits the fact that a local minimum for a neighborhood structure is not necessarily a minimum for another. This allows the VNS to escape from valleys which may not be global minimums. VNS requires the researcher to specify termination conditions; a time limit $\left(\right.$ time $\left._{\max }\right)$ and the size of neighborhood jumps $\left(n_{\max }\right)$. A VNS type procedure is described in Algorithm 2. 
VNS outperforms algorithm 1 when estimation problems become increasingly complex. When problems are simple (typically when $N, G$ are small) the iterative algorithm is faster and equally consistent. The choice of algorithm is at discretion of the researcher. Bonhomme and Manresa (2015) find bias when $N=30$ and $G=10$, which suggests that VNS is optimal for this research. 